\title{
An Overview of Experiments and Numerical Simulations on Airflow and Aerosols Deposition in Human Airways and the Role of Bioaerosol Motion in COVID-19 Transmission
}

\author{
Justus Kavita Mutuku1, Wen-Che Hou' ${ }^{1 *}$, Wei-Hsin Chen ${ }^{2,3,4 *}$ \\ ${ }^{1}$ Department of Environmental Engineering, National Cheng Kung University, Tainan 70101, Taiwan \\ ${ }^{2}$ Department of Aeronautics and Astronautics, National Cheng Kung University, Tainan 70101, Taiwan \\ ${ }^{3}$ Department of Chemical and Materials Engineering, College of Engineering, Tunghai University, Taichung 407302, \\ Taiwan \\ ${ }^{4}$ Department of Mechanical Engineering, National Chin-Yi University of Technology, Taichung 41170, Taiwan
}

\begin{abstract}
Determining the hotspots and deposition efficiencies (DEs) for aerosols in human airways is important for both research and medical purposes. The complexity of the human airways and the breathing process limit the application of in vitro measurements to only two consecutive branches of the human airway. Herein, in-depth information on in vitro experiments and state-of-the-art review on various computational fluid dynamics (CFD) applications and finite element methods on airflow and aerosol motion in both healthy and obstructed human airways are provided. A brief introduction of the application of one-dimensional and two-dimensional mathematical models to investigate airflow and particle motion in the lungs are further discussed. As evident in this review, aerosol deposition in the upper and central human airway regions has been extensively studied under different inhalation statuses and conditions such as humidity as well as different aerosol sizes, shapes, and properties. However, there is little literature on the lower sections of the human airways. Herein, a detailed review of the fundamentals for both in vitro experiments and numerical simulation at different sections of human airways is done. Exceptional features and essential developments in numerical methods for aerosol motion in healthy and diseased human airways are also discussed. Challenges and limitations associated with the applications of in vitro experiments and CFD methods on both human-specific and idealized models are highlighted. The possibility of airborne transmission pathways for COVID-19 has been discussed. Overall, this review provides the most useful approach for carrying out twophase flow investigations at different sections of the human lungs and under different inhalation statuses. Additionally, new research gaps that have developed recently on the role of bioaerosols motion in COVID-19 transmission, as well as the deposition of aerosols in impaired human airways due to coronavirus (COVID-19) are underlined.
\end{abstract}

Keywords: Aerosol physics; Asthma and COPD; in vitro experiment; Numerical methods; Two-phase flow; Deposition efficiencies (DEs); Coronavirus (COVID-19).

\section{NOMENCLATURE}

A Amplitude of the sinusoidal curve (Reynolds number)

$\mathrm{A}_{\text {fold }}$ Amplitude of the folds (cm)

$\mathrm{A}_{0} \quad$ Cross-sectional area of the lumen $\left(\mathrm{cm}^{2}\right)$

C Concentration $\left(\mathrm{cm}^{-3}\right)$

$\mathrm{C}_{\mathrm{D}} \quad$ Drag coefficient

DF Deposition fraction

\footnotetext{
* Corresponding author.

E-mail address: whou@mail.ncku.edu.tw (W.C. Hou); weihsinchen@gmail.com; chenwh@mail.ncku.edu.tw (W.H. Chen)
}

$\begin{array}{ll}\mathrm{D} & \text { Diameter }(\mathrm{mm}) \\ \mathrm{d}_{\mathrm{p}} & \text { Particle diameter }(\mu \mathrm{m}) \\ \mathrm{F} & \text { Force }(\mathrm{N}) \\ \mathrm{G} & \text { Generation of Weibel's airway } \\ \mathrm{G}_{\mathrm{k}} & \text { Turbulent kinetic energy } \\ \mathrm{G}_{\mathrm{w}} & \text { Specific dissipation rate } \\ \mathrm{L}_{\mathrm{A}} & \text { Length of the real airway }(\mathrm{m}) \\ \mathrm{L}_{\mathrm{M}} & \text { Length of the geometric model }(\mathrm{m}) \\ \mathrm{m}_{\mathrm{p}} & \text { Mass of a single particle }(\mu \mathrm{g}) \\ \mathrm{n} & \text { Number of folds } \\ \mathrm{P} & \text { Pressure }(\text { Pa) } \\ \mathrm{Q} & \text { Flow rate }\left(\mathrm{L} \mathrm{s} \mathrm{s}^{-1}\right) \\ \mathrm{R} & \text { Radius (mm) } \\ \mathrm{r} & \text { Radial coordinate } \\ \mathrm{Re} & \text { Reynolds number }\end{array}$


t Time (s)

$\mathrm{u}_{\mathrm{p}} \quad$ Particle velocity $\left(\mathrm{m} \mathrm{s}^{-1}\right)$

$\mathrm{U}_{\mathrm{A}} \quad$ Velocity at the real airway $\left(\mathrm{m} \mathrm{s}^{-1}\right)$

$\mathrm{U}_{\text {mean }}$ Average velocity at the airway's entrance $\left(\mathrm{m} \mathrm{s}^{-1}\right)$

$\mathrm{U}_{\max }$ Max velocity at the airway's entrance $\left(\mathrm{m} \mathrm{s}^{-1}\right)$

$\mathrm{U}_{\mathrm{M}} \quad$ Velocity at the geometric model $\left(\mathrm{m} \mathrm{s}^{-1}\right)$

V Control volume

\section{Greek Letters}

$\rho \quad$ Density $\left(\mathrm{kg} \mathrm{m}^{-3}\right)$

$\sigma \quad$ Stress $\left(\mathrm{N} \mathrm{m}^{-2}\right)$

$\mu \quad$ Viscosity Coefficient

$v_{n} \quad$ Averaged inlet velocity of parent branch $\left(\mathrm{m} \mathrm{s}^{-1}\right)$

$\alpha_{\mathrm{f}} \quad$ Fluid volume fraction

$\theta \quad$ Angular coordinate $\left(^{\circ}\right)$

\section{Subscripts \\ $\mathrm{p}$ particle \\ $\mathrm{H}$ hydraulic \\ mean average value \\ peak peak value}

\section{INTRODUCTION}

In vitro experiments and computational fluid dynamics (CFD) coupled with finite element method (FEM) have been used as tools for investigating airflow and aerosol motions in human airways for a few years. They are used to investigate the differences in deposition efficiencies (DEs) and deposition patterns of toxic and pharmaceutical aerosols for both healthy and obstructed human airways. Those approaches are useful in the assessment of the performance of existing drug-aerosol delivery technologies to the human lungs (Asgharian et al., 2001; Darquenne, 2012). Findings from these studies can be applied in the accurate estimation of risk levels caused by toxic aerosols or in design modifications to overcome the limitations of inhalers used by patients with respiratory diseases (Kolanjiyil and Kleinstreuer, 2017; Chen et al., 2018a).

Investigations in the current and past centuries have linked air pollution to a wide range of acute and chronic health defects (Brook et al., 2010; Chowdhury et al., 2019). A case in point is the statistically significant association between long-term exposure to fine particulate matter (PM) and reduced life expectancy (Asadi et al., 2020). Although this information is only available for developed and middleincome countries in the world countries, model estimations depict a worse situation in developing countries whose true situation remains conclusively unknown (Cohen et al., 2005; Soriano et al., 2017). Reports on the relationship of some aspects of PM, for instance, chemical composition, toxicity, and particle size show an inverse relationship between toxicity and PM's size (Chen et al., 2019; Li et al., 2020b). Consequently, fine $\left(\mathrm{PM}_{2.5}\right)$ and ultra-fine PMs tend to be the most toxic among the total suspended solids (Valavanidis et al., 2008; Zhang et al., 2018).

There is a fascinating but not very conclusive understanding of the possible pathways that associate exposure to $\mathrm{PM}_{2.5}$ and mortality due to cardiovascular diseases (Brook et al.,
2010; Hwang and Park, 2019). Despite $\mathrm{PM}_{2.5}$ affecting the entire population, the adverse impacts are worse for special groups such as infants, the elderly, and patients with obstructive conditions as they experience the highest deposition efficiencies (Longest et al., 2006; Chen et al., 2012; Adeloye et al., 2015). Common obstructive pulmonary diseases include chronic obstructive pulmonary disease (COPD), asthma, cystic fibrosis, and acute respiratory distress syndrome. Epidemiological reports show that the prevalence of COPD and asthma are the highest among the obstructive diseases (Mathers and Loncar, 2006; Mannino and Buist, 2007; Adeloye et al., 2015; Soriano et al., 2017). They are both characterized by persistent and limited airflow inside the lungs and are usually exacerbated by inhalation of toxic gasses and PM (Viegas et al., 1996). Therefore, past studies have mostly focused on airflow, aerosols transportation, transformation, and deposition inside healthy and obstructed human lungs during breathing (McCreanor et al., 2007; Zhang and Papadakis, 2010; Chen et al., 2012).

Meanwhile, coronavirus disease 2019 (COVID-19), which broke out in December 2019, has been shown to cause deadly cases of pneumonia and is, therefore, receiving a great deal of attention lately. This disease has been shown to cause a $3.4 \%$ mortality rate globally according to the estimate from WHO as of March 2020. Analysis of radiographic and computed tomography (CT) findings of COVID-19 patients showed the presence of patchy, confluent, or nodular shaped lesions and pulmonary opacities concentrated mostly in the peripheral lungs (Yoon et al., 2020). A statistical analysis of the dominant shapes of lesions showed that patchy to confluent lesions were more dominant as compared to the nodular ones. Further, CT imaging studies have shown that the lesions are more concentrated on the lower lobes as well as the dorsal part of the lungs (Çinkooğlu et al., 2020). According to the radiologic evidence presented in a study by Li et al. (2020a), the presence of edema and acute lung injury are common in critical stages of patients with severe COVID-19. Acute lung inflammation and long-term damage to the alveolar walls are among the main adverse effects suffered by COVID-19 survivors (Hosseiny et al., 2020; Xu et al., 2020b). Permanent lung damage associated with the disease presents a new challenge of understanding deposition patterns and efficiencies for toxic, pharmaceutical, or biological aerosols in patients after recovery.

To study the motion of aerosols such as PM and bioaerosols such as bacteria and viruses, their size distributions are important. Coronaviruses such as COVID-19, which is the cause of the latest pandemic of respiratory tract infections, have an average size of between 65 and $125 \mathrm{~nm}$, with an envelope diameter and spikes measuring about $80 \mathrm{~nm}$ and $20 \mathrm{~nm}$, respectively (Velavan and Meyer, 2020). The size of aerosols released during coughing and sneezing are very important in studying airborne infectious disease transmission. Their sizes have been shown to vary in healthy and diseased individuals. For healthy individuals, droplets were found to range between 341.5-398.1 $\mu \mathrm{m}$ for unimodal distribution (Han et al., 2013). On the other hand, individuals affected by influenza were found to sneeze droplets whose size ranged between 0.35 to $10 \mu \mathrm{m}$ (Lindsley et al., 2012). 
The geometry of the human lung is very complex. Therefore, to study the motions of aerosols inside the lungs, in vitro experiments and CFD analysis usually employ simplified geometries (Lennon et al., 1998; Delvadia et al., 2012). The main simplified models include (1) Weibel's geometry which is asymmetrical and with 23 generations and (2) Horsfield's asymmetrical geometry (Weibel, 1963b; Horsfield and Cumming, 1967). Other geometries developed later, for instance, by Hammersley and Olson (1992), are more suitable for investigations in the sixth to twelfth generations (G6-G12).

Traditionally, investigations about the deposition efficiencies for aerosols inside the human lungs were conducted using experiments (Chang and El Masry, 1982; Lennon et al., 1998). It is 5 decades since the first in vitro measurements for airflow and particle motion inside the lungs were done. Currently, this approach presents a great challenge due to the limited ability to accurately assess instantaneous airflow velocity and pressure as well as the DEs (Lambert et al., 2011). The development and advancement of computing capability in the world have enhanced the application of FEM and CFD models to carry out investigations on airflow and particle deposition in human airways (Chen et al., 2012; Rahimi-Gorji et al., 2015).

Important items before the implementation of a CFD study include the generation of geometry, solving the governing equations along with appropriate boundary conditions, and sometimes incorporating user-defined functions (UDFs). The shape and size of geometry are not only dependent on the generation of the human airways under investigation but also on whether it is healthy or affected by a disease (Sul et al., 2014; Chen et al., 2018a). COPD has been represented by an axisymmetric constriction at the center of a bifurcation, while asthma has been represented by sinusoidal folds at the circumference of the affected bifurcation (Yang et al., 2006; Zhang and Papadakis, 2010). Typical boundary conditions imposed for airflow include velocity distribution at the inlet, no-slip boundary condition along the walls, and pressure at the outlets (Zhang and Kleinstreuer, 2002).

In COPD cases, investigations on airflow have attributed the shortness of breath to the presence of stagnation and recirculation zones at the proximity of the obstructed bifurcation (Luo et al., 2007; Chen et al., 2012; Mutuku and Chen, 2018). Pressure distributions in COPD showed that jet flow phenomena at the cross-section affected by the obstruction resulted in low pressures which were inadequate to drive the required airflow mass to the later sections of the human airway (Yang et al., 2006). Skewed airflow velocities influenced the mass flow ratios at bifurcations in the generations affected by the obstruction and subsequent ones (Mutuku and Chen, 2018). Sudden reduction in the effective cross-sectional area for asthma cases caused increased airflow velocities and high complex secondary flows, which in turn led to higher deposition fractions for $\mathrm{PM}_{2.5}$ as compared to healthy human airways (Chen et al., 2018a). Airflow resistance, which is normally represented by the ratio of total pressure drop, has been applied to characterize and evaluate obstructions in the human lungs (Sul et al., 2014). Previous research has shown that the pressure drop is usually directly proportional to the airflow rate due to amplified secondary flow.

Since the development of CFD, different types of fluid flow have been thoroughly described, including continuous flow systems in the industrial, environmental, and physiological applications (Chen, 2001a; Longest et al., 2006; Chen et al., 2011; Zhang et al., 2019). The physiological processes include airflow in the airways and blood flow inside the human body (Soni and Aliabadi, 2013; Chen et al., 2018c). CFD has matured into a proper tool whose application in describing airflow in the human airways has almost replaced the traditional in vitro experiments. This increased adoption of CFD methods for airflow analysis has been aggravated by the need to produce detailed results on airflow as well as the high costs and huge time consumed during in vitro experiments (Solchenbach and Trottenberg, 1988). Additionally, CFD blends visualization techniques as well as mathematical physics and methods for the production of optimized results (Chen, 2001b).

Previously reviews have been conducted on the applications of CFD to study the deposition of aerosol medicine in a whole lung airway model by Longest et al. (2019). Another review by Islam et al. (2020) covered the recent developments on airflow analysis and particle deposition in both upper and lower regions of human airways. Furthermore, particle clearance mechanisms in the lungs have also reviewed (Hussain et al., 2011). The simulations of particle formation and localized deposition in human airways using 1-D, 2-D, and 3-D models were reviewed by Guzman (2020). Despite other authors writing reviews on aerosol deposition and particle clearance in human lungs, none has combined particle deposition and lung clearance mechanism. This review fills the gap by reviewing the application of experiments and CFD with FEM in the assessment of airflow as well as aerosol motion and deposition in healthy and deformed human airways. Fundamentals for in vitro experiments involving airflow and particle motion inside the human lungs are discussed. Additionally, those for numerical simulation, for instance, simplified geometries of the human lungs, CFD models for different sections of the human airway are covered. Dominant lung clearance mechanisms at different sections of the human airways are briefly discussed. Exceptional features and essential aspects of results from both experiments are CFD analyses are also discussed.

\section{HUMAN AIRWAY STRUCTURE}

Gaseous exchange between the atmosphere and the human blood is accomplished through the human respiratory system. Upon inhalation, air travels through the nose, pharynx, larynx, and into the trachea, after which it goes into one of the two bronchi that lead the way into the left and right lungs. The two bronchi divide into smaller and smaller bronchioles until they reach the alveoli. The alveoli, which are sac-like structures, mark the end of the lungs and the region responsible for gaseous exchange between the inhaled air and the blood in the circulatory system (Horsfield and Cumming, 1968).

\section{Geometric Models for Human Airways}

In vivo measurements on the deposition efficiencies and airflow dynamics inside the lungs are impossible due to the 
delicate and complex nature of the human airways. Therefore, in vitro measurements and numerical simulations have been applied in the investigations for airflow as well as particle motion and deposition. Due to the complex nature of the human lungs, in vitro experiments on the human lungs require simplification of the lungs' geometry. Several researchers have developed simplified lung geometries (Weibel, 1963b; Horsfield et al., 1971; Yeates and Aspin, 1978; Hammersley and Olson, 1992; Van Ertbruggen et al., 2005; Lindsley et al., 2012; Chen et al., 2017; Zhao et al., 2020). However, only two of these are commonly used for in vitro experiments and numerical analysis; they are Horsefield's model (Horsfield and Cumming, 1968) and Weibel's model (Weibel, 1963a). These geometric models are applied for in vitro experiments or numerical simulations to investigate airflow or particle motion and deposition inside the human airways. In some studies, CT scans and magnetic resonance imaging (MRI) measurements have been applied to develop more realistic geometric models. However, airflow dynamics, aerosol motion, and deposition in the human airways face tremendous intersubjective inconsistencies and therefore the results from such human-specific studies cannot be projected to the entire population. Furthermore, curvatures and anatomy of the real human airways are more complicated compared to the simplified models and as such, their airflow patterns are equally complicated (Hwang and Park, 2019). Despite the use of CT scans and MRI measurements providing the most realistic geometries, they cannot provide the dimensions of the bifurcation beyond the $7^{\text {th }}$ or $9^{\text {th }}$ generation due to inadequate clarity of the scanned images (Walters and Luke, 2010). This makes simplified models more attractive as compared to real ones obtained from CT scans for application in studies involving the human airways, especially for central and lower sections of the lung.

In the study of airflow dynamics and particulate phase motion in the trachea-bronchial bifurcations, a huge task lies in striking a balance between ease of measurement and physiologically realistic airway geometry. The Weibel's geometry assumes a symmetrical geometry, while the Horsfield's model assumes an asymmetrical structure (Weibel, 1963b; Horsfield et al., 1971). Scientific evidence suggests that the human lung is asymmetrical and the number of generations in a particular pathway is variable (Horsfield and Cumming, 1968; Chen et al., 2020). However, Weibel's geometric model which is idealized, regular, and symmetrical remains the most popular due to its ability to provide sufficient information on gas and particulate flow within a short computational time.

The walls in airways are commonly assumed to be rigid and smooth with a circular cross-section (Chang and El Masry, 1982; Chen et al., 2018a). The concept of hydraulic diameter is important as it equates the circular cross-sections in idealized models to the bronchial surface over which airflow experiences a shear force in the real human airway (Hammersley and Olson, 1992). The hydraulic diameter is expressed as

$D_{H}=\frac{4 \times \text { Area }}{\text { perimeter }}$ where $D_{H}$ is the hydraulic diameter for the idealized model, while the area and perimeter are measured from the real airway geometry.

Historically, whole lung-semi-empirical models were applied to establish the deposition patterns and airflow phenomenon in the human airways. However, a more feasible approach has been developed recently and it involves the application of multistage modeling with the development of large scale models representing the central airways and small scale models to represent peripheral airways (Kolanjiyil and Kleinstreuer, 2017). The approach is aimed at obtaining a whole lung airway model which is physiologically accurate. Investigations on airflow and particle motion using the resultant geometric representations can be used to build an understanding of the whole human lung.

According to a study by Park and Wexler (2007), there is a significant degree of mixing, especially in Weibel's bifurcation. As air advances to the terminal airways, the aggregate crosssectional area of the human airways increases, and this amplifies recirculation phenomena and hence increases the mixing, especially with the pulsating airflow. It is important to understand the fluid mechanics for airflow inside the human airways, especially for area expansion, curvatures, secondary flow phenomena, flow re-organization, and stagnation and recirculation zones in each bifurcation (Hammersley and Olson, 1992; Lambert et al., 2011).

\section{Weibel Geometric Model}

According to the study of Weibel (1963b), the tracheobronchial system can be simplified using a dichotomous branching network of pipes and a total of 23 levels of ducts (bifurcations). The bifurcations are numbered depending on how far downstream they are from the trachea. Therefore, the trachea is G0, the left and right bronchi which are both $\mathrm{G} 1$, the four branches after the bronchi G1 are G2, and so forth until the last section of the alveoli (G20-G23). A simplified representation of Weibel's model is presented in Fig. 1(a). It is widely accepted that the application of a reduced number of branches with suitable boundary conditions can give results with an acceptable degree of accuracy if the region of interest is not at the outlet branches (Sul et al., 2014). A 4 generations bifurcation for a healthy human airway is shown in Fig. 2(a). In this model, the human lung geometry can be split into three main regions; G0-16 is the conductive zone, G17-19 is respiratory bronchioles, and G20-23 is composed of alveoli ducts and alveoli. The bifurcations have a constant length to diameter ratio (L/D) which is approximately 3 . The ratio of the parent bifurcation diameter to that of the child $\left(\mathrm{D}_{\mathrm{n}} / \mathrm{D}_{\mathrm{n}+1}\right)$ is also constant in this model and ranges from 1.17 to 1.5 (Weibel, 1963a).

\section{Horsfield GEOMETRIC MODEl}

This model was aimed at capturing the effects of asymmetry on airflow dynamics and particle deposition (Horsfield and Cumming, 1967). The effects of asymmetry on airflow and particle motion increases as air advances from the oro-nasal cavity towards the alveoli region. The approach by Horsfield and Cumming (1967) applied formulas by which the asymmetry of the dichotomous branching 
could be represented. Details provided in the model include the angle of the branches, the radius of the curvature, and the cross-sectional shape. The numbering of the bifurcations also differs from the one proposed by Weibel (1963b), in the sense that bifurcations are numbered starting from the alveoli region. (Horsfield and Cumming, 1967). A typical solid geometry and mesh for a model adapted from Horsfield's model are presented in Fig. 1(b).

\section{Other Models}

A few other irregular dichotomy models have been proposed based on morphometric data from Horsfield's model (Yeates and Aspin, 1978; Van Ertbruggen et al., 2005). Yeates and Aspin, (1978) carried out a study on the physiological implications of the morphological structure proposed by Horsfield, whereby mathematical expressions for the bifurcation system of the intralobular bronchi from the

(a)

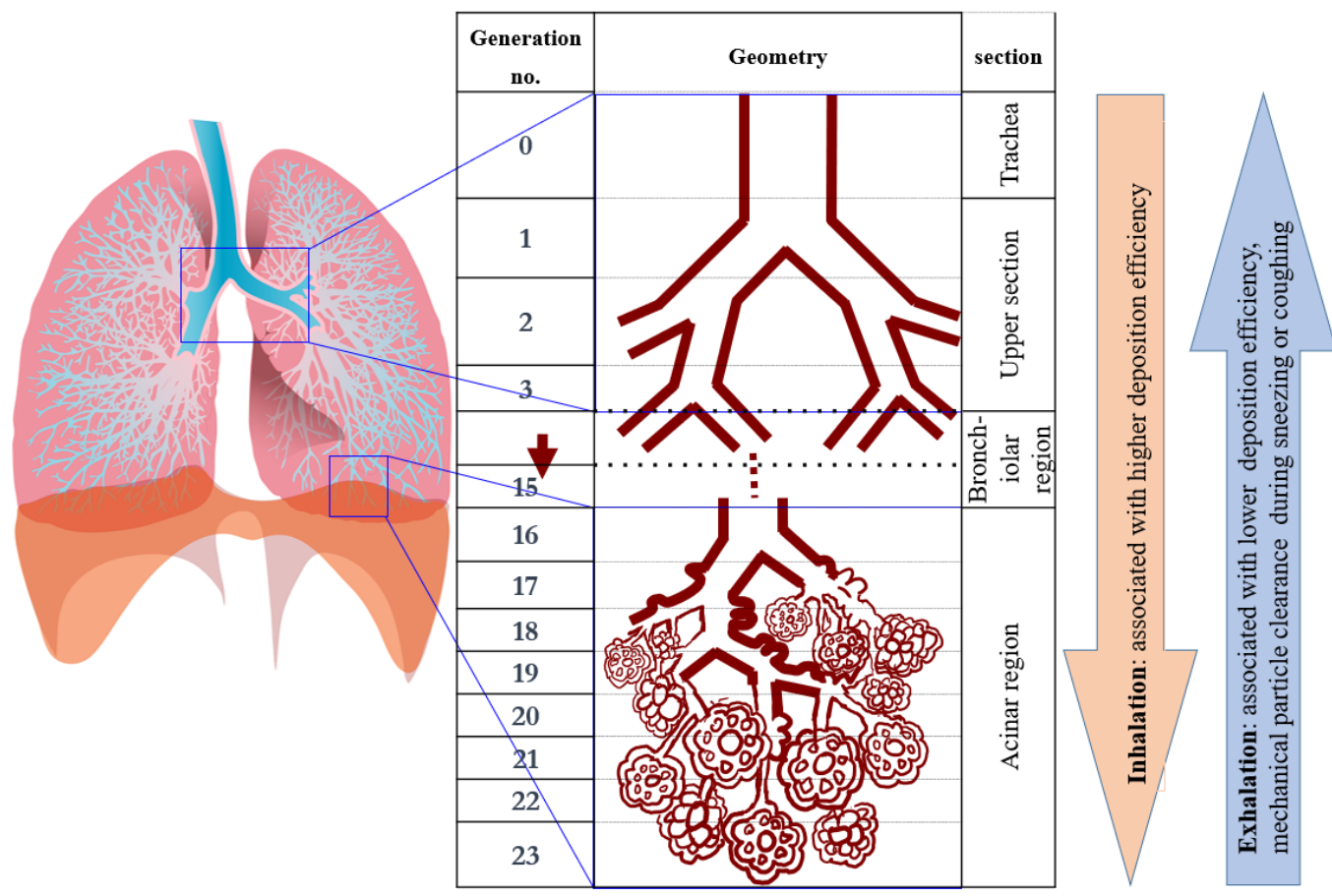

(b)

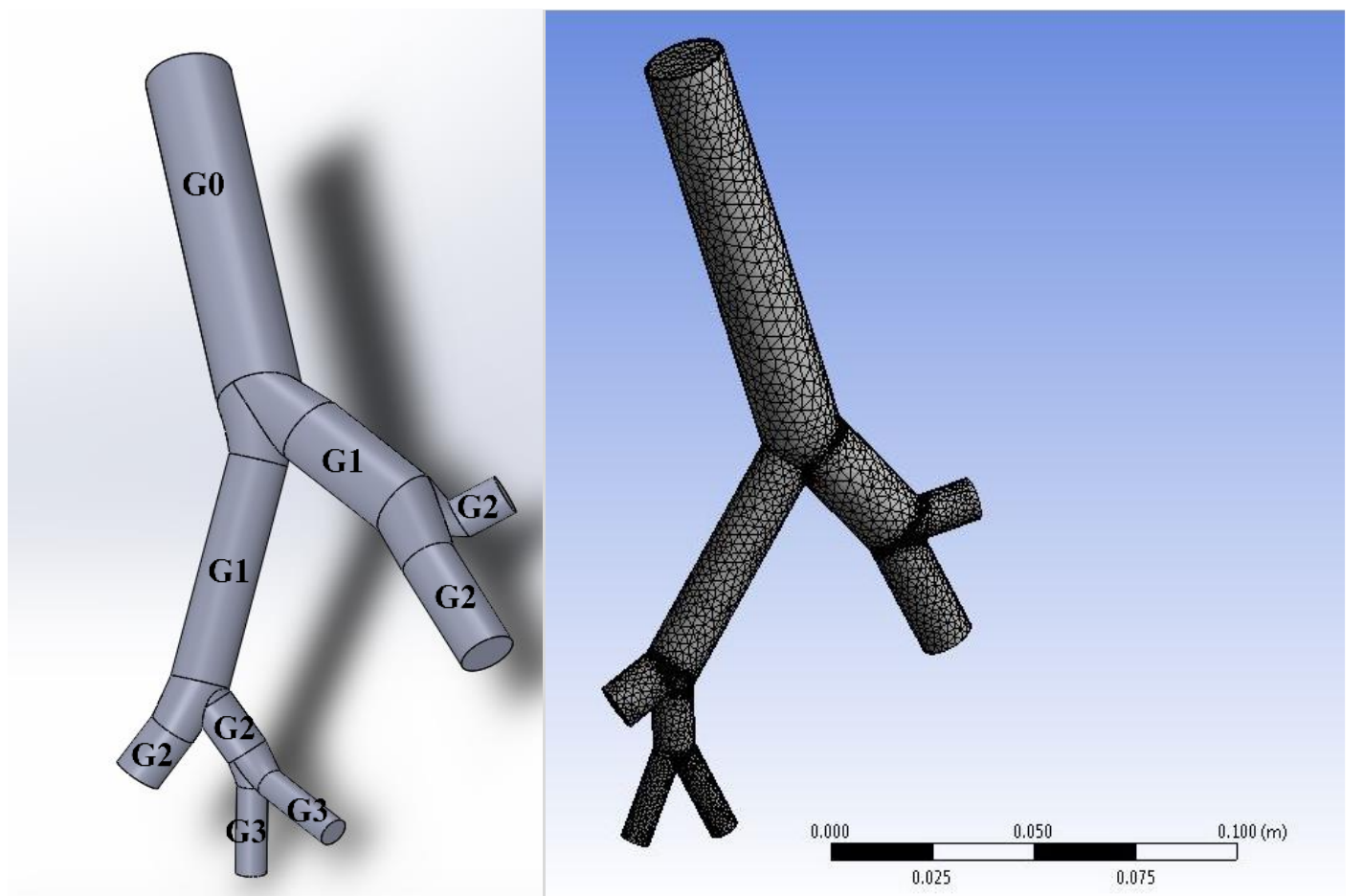

Fig. 1. (a) A representation of Weibel's symmetrical models of generations 0-23 and (b) A representation of the G0-G3 of the Horsfield's asymmetrical model. 
trachea to the alveoli were described. Additional anatomical models have also been established using mathematical algorithms and imaging techniques (Tgavalekos et al., 2007; Velavan and Meyer, 2020; Xu et al., 2020b). The latest airway geometry model was developed by Lindsley et al. (2012) and it described the first 17 generations of an asymmetrical human airway geometry. A more practical cadaver model was developed to handle smaller airways for bifurcations between G6 and G12 (Hammersley and Olson, 1992). A mathematical method of obtaining a physiologically accurate geometry for the first five generations of the human airway was developed by Zhao et al. (2020). Semi-automatic approaches have been developed to help in the development of the lung's morphological structure (Sauret et al., 1999). In a study by Lindsley et al. (2012), high-resolution tomography coupled with image processing algorithms were applied to develop precise models of the human airways up to the $17^{\text {th }}$ generation of the Horsefield's geometry. Another hybrid model using more than two techniques to characterize the geometry was by Van Ertbruggen et al. (2005), which used the work by Horsfield and Cumming (1967) for characteristics of individual generation coupled with imaging techniques to obtain local branch orientations.

\section{Anatomical Features of Diseased Human Lungs}

Since asthma and COPD are the most prevalent obstructive pulmonary diseases, there is a relatively higher volume of literature covering aerosol motion and deposition in human airways affected by these conditions (Yang et al., 2006; Luo et al., 2007; Zhang and Papadakis, 2010; Chen et al., 2018a). Geometric characteristics of the obstructed human airways such as for asthma and COPD can be represented by slightly altered geometries from the regular idealized ones. Asthmatic human airways are usually represented by uniformly distributed folds along the circumference of the affected generation (Zhang and Papadakis, 2010; Chen et al., 2018a).

According to the study of Zhang and Papadakis (2010), a human airway affected by asthma can be represented as a circular cross-section surrounded by several sinusoidal folds which are distributed along the circumference. The equation can be expressed in the polar coordinate system as:

$r(\theta)=R+A_{\text {fold }} \cos (n \theta)$

where $r, \theta$ and $R$ are the radial coordinate, angular coordinate, and effective radius of the affected cross-section. Additionally, $A_{\text {fold }}$ and $n$ stand for the amplitude of the fold in centimeters and the number of folds in the affected cross-section, respectively. A typical configuration of the asthmatic airway discretized with $40 \%$ of normal lumen area and 10 folds is shown in Fig. 2(b).

On the other hand, airways affected by COPD are represented by axisymmetric constriction in one or more of the bifurcations (Yang et al., 2006; Chen et al., 2012). A typical figure of a human airway affected by COPD as shown in Fig. 2(c).

The lung damages caused by COVID- 19 will affect airflow as well as aerosol motion and deposition inside the human airways of survivors. In previous studies, based on

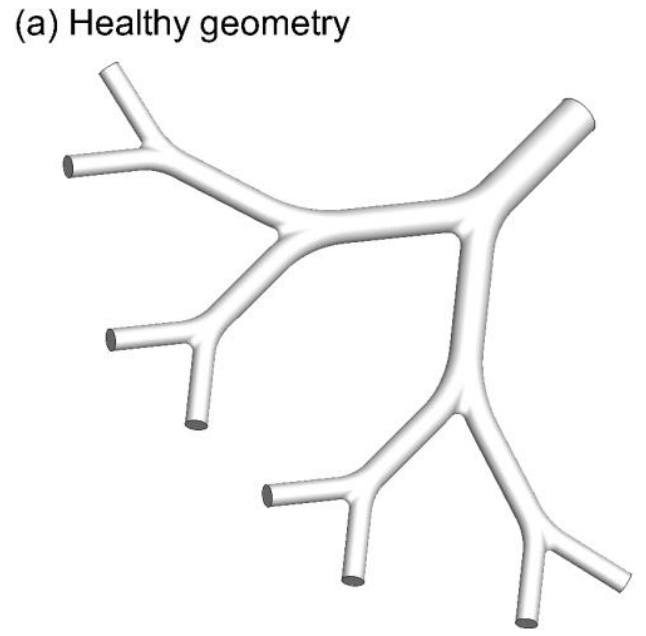

(b) Geometry affected by asthma

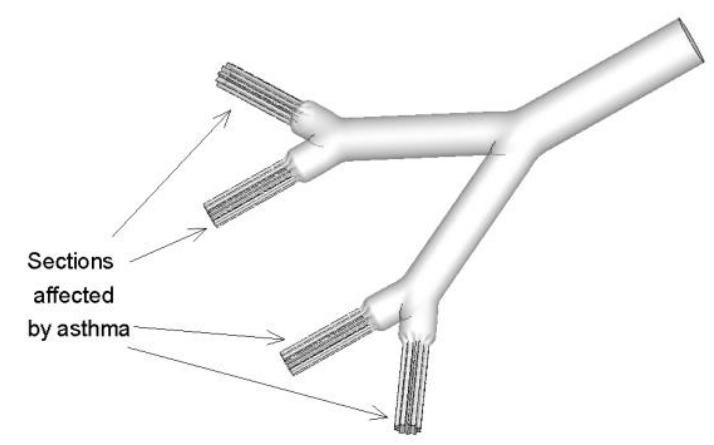

(c) Geometry affected by COPD

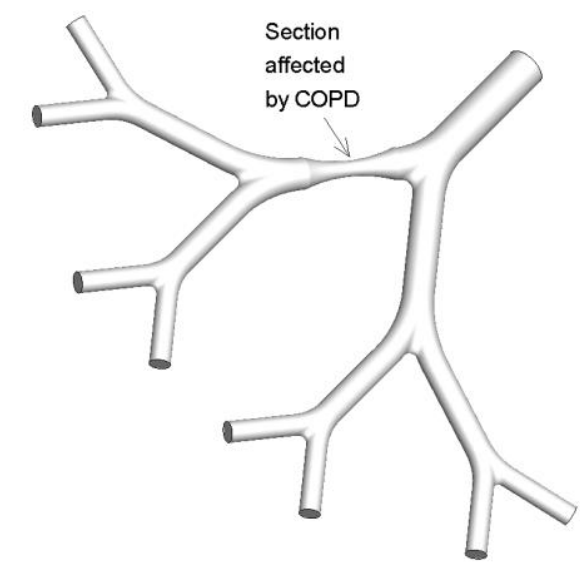

Fig. 2. Typical geometries for (a) healthy human airway, (b) human airway affected by asthma, and (c) human airway affected by COPD.

human-specific airway geometries, CT scans have provided images that are clear enough for the reproduction of $3 \mathrm{D}$ geometries up to the G9 of the human airways. The lesions associated with COVID -19 are mostly concentrated in the alveolar region, and therefore, it is difficult if not impossible 
to obtain CT images at a clarity level which would be adequate for the production of 3D geometries of the diseased regions. Therefore, new approaches are needed to carry out investigations on airflow and particle motion in the lungs of COVID-19 survivors.

\section{Whole Lung Airway Model vs. Localized Simulations.}

There have been few attempts to simulate the resistance of flow, and deposition efficiency in the entire human lung. A summary of the studies has been presented in Fig. 3. In a study by Chen et al. (2017), the resistance of flow in the upper airway was found to contribute $45-81 \%$ of the total resistance of the entire human lung depending on the frequency of ventilation. During the study, hybrid 3D geometries for the upper, central, small airways, and alveoli were used. Some of the generations between G4 and G6 were truncated. In a study on the deposition of $1-30 \mu \mathrm{m}$ particles in the tracheobronchial generations between the mouth to G10, deposition mostly happened in the large- and medium-sized generations (Ma and Lutchen, 2009).

The latest state-of-the-art approach in CFD involves the application of partially resolved models of a truncated airway tree. After truncation, appropriate boundary conditions are imposed on the truncated sections by applying prior pressure conditions or stochastically coupled boundary conditions. A truncated model was used by Tena et al. (2015) whereby the same velocity vector fields were imposed on the truncated sections as the corresponding sections of the developed branches of the airway. In another study by Walters and Luke (2010), where $50 \%$ of the airway paths were truncated, static pressure values at corresponding sections of the remaining bifurcations were used as the boundary conditions at the truncated sites. In a study by Gemci et al. (2008) a 17generation model was partially solved using 1,453 bronchi rather than 131,072. This was achieved through truncation and duplication of the boundary conditions to cater for the truncated sections. In a study by Walters and Luke (2010), a bifurcation angle of $70^{\circ}$ was applied for a geometry consisting of G4-G12, the plane for each bifurcation was selected randomly for angles between $0^{\circ}$ and $180^{\circ}$. In this study, branches were truncated past G6 such that only one branch followed all through to G12. Stochastically coupled boundary conditions were imposed on the truncated sections.

On the other hand, studies on localized deposition of particles include the work of Nowak et al. (2003) where a numerical analysis for airflow and $10 \mu \mathrm{m}$ particle motion was carried out based on a four-generation Weibel's model

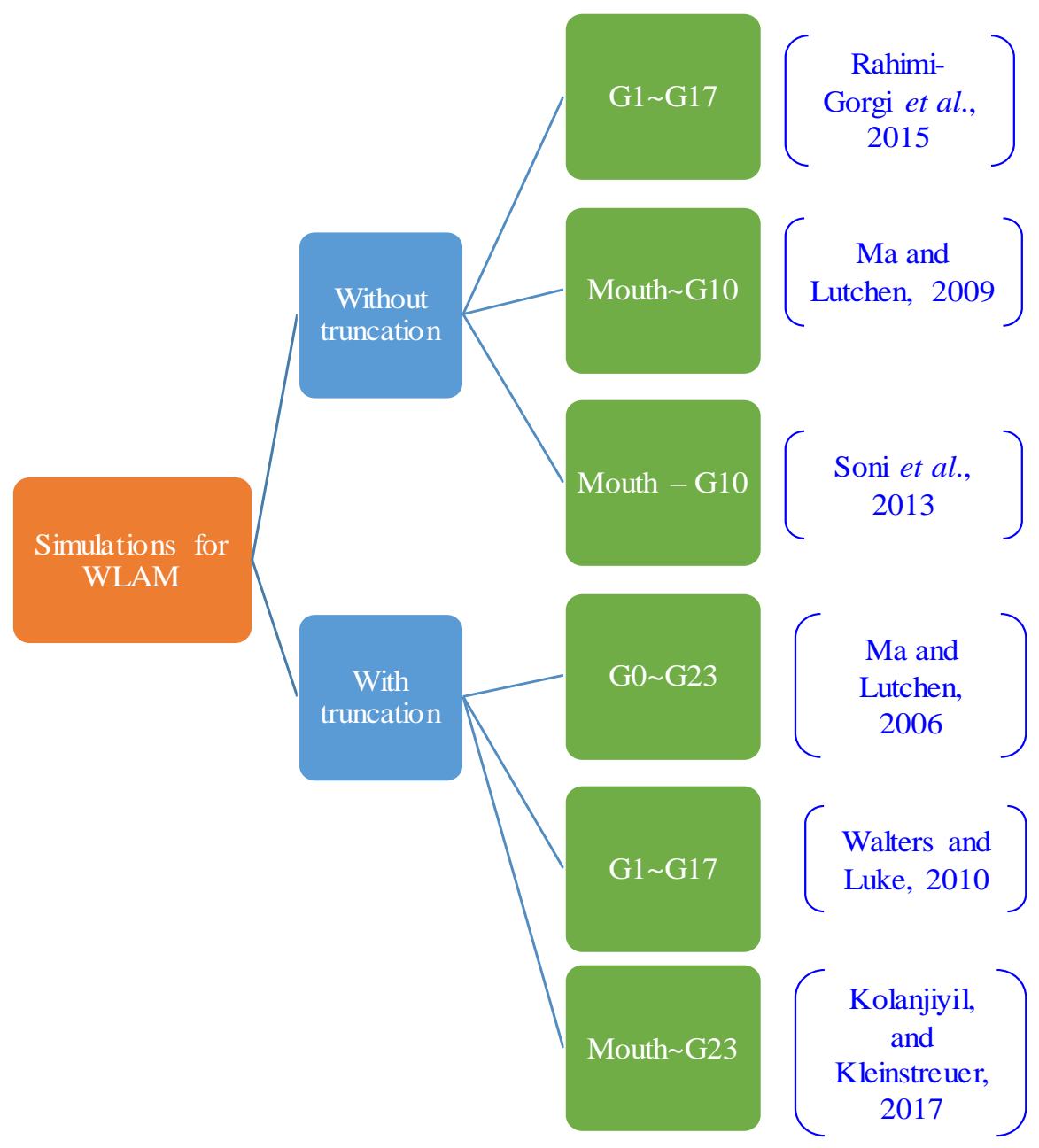

Fig. 3. Attempts towards carrying out aerosol motion investigations in a whole lung airway model. 
(G0-G3) and a cadaver lung cast. Results from the deposition efficiencies done for both inhalation and exhalation flow conditions showed a maximum deposition of $12 \%$ in the carina region that succeeds generation 2 for unsteady inhalation using Weibel's geometry. The maximum DE of $6.5 \%$ for the geometry from the CT scan was highest at G0 for both steady and unsteady inhalation conditions (Hwang and Park, 2019). In an in vitro experiment, by Lennon et al. (1998) whereby deposition efficiencies were compared for nasal and oral inhalation, the maximum deposition efficiency of $43.6 \%$ occurred during nasal inhalation at the nasal region as compared to $5.4 \%$ at the oral cavity during oral inhalation. The effect of cartilage on airflow in the trachea and the main bronchi were investigated using CFX and Fluent solvers (Russo et al., 2008). Results showed that for a laminar flow characterized by $15 \mathrm{~L} \mathrm{~min}^{-1}$ at the inlet DEs using Fluent exceeded those obtained using CFX by an average of $2.4 \%$. However, for a turbulent flow of $60 \mathrm{~L} \mathrm{~min}^{-1}$, the DEs of Fluent fell behind those of CFX by about $4.2 \%$ for a smooth airway channel, and they were equal for ringed trachea and bronchi. Further details on localised deposition are tabulated in Table 1.

The whole lung airway model can provide information about the airflow dynamics, particle motion, and deposition of particles inside the human airways. However, the degree of details required to achieve an improved understanding of regional deposition is not practical while using a whole lung airway model. This reason makes localized particle deposition models more popular. Additionally, accurate prediction of DEs in hotspots and other vulnerable sites can provide more relevant methods for the assessment parts of the respiratory system which are more prone to injury or diseases due to higher deposition efficiencies of aerosols (Hofmann et al., 1995; Nazridoust and Asgharian, 2008).

\section{FUNDAMENTALS OF IN VITRO EXPERIMENTS}

For a long time, experiments have been performed to understand airflow resistance in the human lungs, mixing of the intrapulmonary gases and deposition of particles from ambient air (Yanai et al., 1992; Cheng et al., 1999). The main goal for these experiments is usually to shed some light on the airflow dynamics inside the human lungs and also the factors influencing particle deposition inside them. The setup for an in vitro analysis is shown in Fig. 4.

\section{Generating Casts}

Solid casts to represent the human airways are applied in experiments. Their dimensions are usually human-specific or following popular simplified human airway geometries. Solid tubular models are usually constructed to represent the airway bronchus from materials such as acrylic plastic (Perspex), silicone rubber, milled steel blocks, premade Yconnectors, bored aluminum, or plumbing fixtures (Chang and El Masry, 1982; Lennon et al., 1998). Even though the physical geometry is usually at a larger scale to ensure ease of data collection, the Reynolds number should be kept constant to ensure dynamic similarity, as expressed in the following equation (Chang and El Masry, 1982).
$\frac{U_{M} L_{M}}{v_{M}}=\frac{U_{A} L_{A}}{v_{A}}$

where $U$ and $L$ represent linear velocity and dimension, respectively, while $v$ designates the kinematic viscosity of the gas phase. The subscripts $M$ and $A$ denote the geometric model and the real airway, respectively.

To conduct experiments on obstructed airways in the lungs, copper tubes, which are packed with steel capillary tubes, are applied as obstructions inside the tubular model. The longer the resistor, the more severe the obstruction (Chang and El Masry, 1982). Plastic conic resistors provide the transition from the airway terminals to resistors. A precision metering valve is applied to control the airflow rate during both inhalation and exhalation.

\section{Methods of Measuring Flow Velocity and Pressure Distribution}

Airflow velocity is usually constant for experiments. As can be seen on the VOSviewer map in Fig. 5 airflow is among the most important parameters in aerosol motion inside the human airways. Axial flow velocities are usually measured using hot-wire anemometer probes. The working mechanisms of the wire probes involve the application of the cooling effect of the wire due to airflow to estimate the velocity of air at the cross-section fitted with the anemometer wire (Chang and El Masry, 1982; Isabey and Chang, 1982; Cheng et al., 1999). Secondary flow velocities are captured using still photographs by continuous frontal illumination with an angle of $45^{\circ}$ as the incidence angle (Schroter and Sudlow, 1969). Pressure drop over a given lateral length is usually measured using a sensitive differential pressure transducer (Chang and El Masry, 1982; Yanai et al., 1992). In a study by Stapleton et al. (2000), overall pressure drop during a turbulent flow in a mouth-throat geometry was measured by attaching a pressure transducer to both the inlet and exit using pressure traps.

\section{Estimating Deposition Patterns and Respective Deposition Efficiencies}

The aerosol deposition is among the most important aspects of studies on aerosol motion in the human airways as can be seen in Fig. 5. The application of chemicals with unique properties under illumination is helpful in the estimation of deposition efficiencies. In an experimental study by Lennon et al. (1998), regional deposition efficiencies for fluorescent particles with diameters of $0.3 \mu \mathrm{m}$ and $0.7 \mu \mathrm{m}$ were estimated by measuring the fluorescent intensity using a fluorescence spectrophotometer. Overall deposition efficiency was estimated by comparing the number of particles injected to the ones which exited the cast at the outlet. Aerosol deposition in a study by Cheng et al. (1999) was investigated using different sizes of polystyrene latex fluorescence particles. Fluorescent content and consequently the deposition fractions were estimated using a fluorescence spectrometer. An aerodynamic particle sizer which gives the particle size and the number concentration can be used to measure the total deposition (Häußermann et al., 2002). 


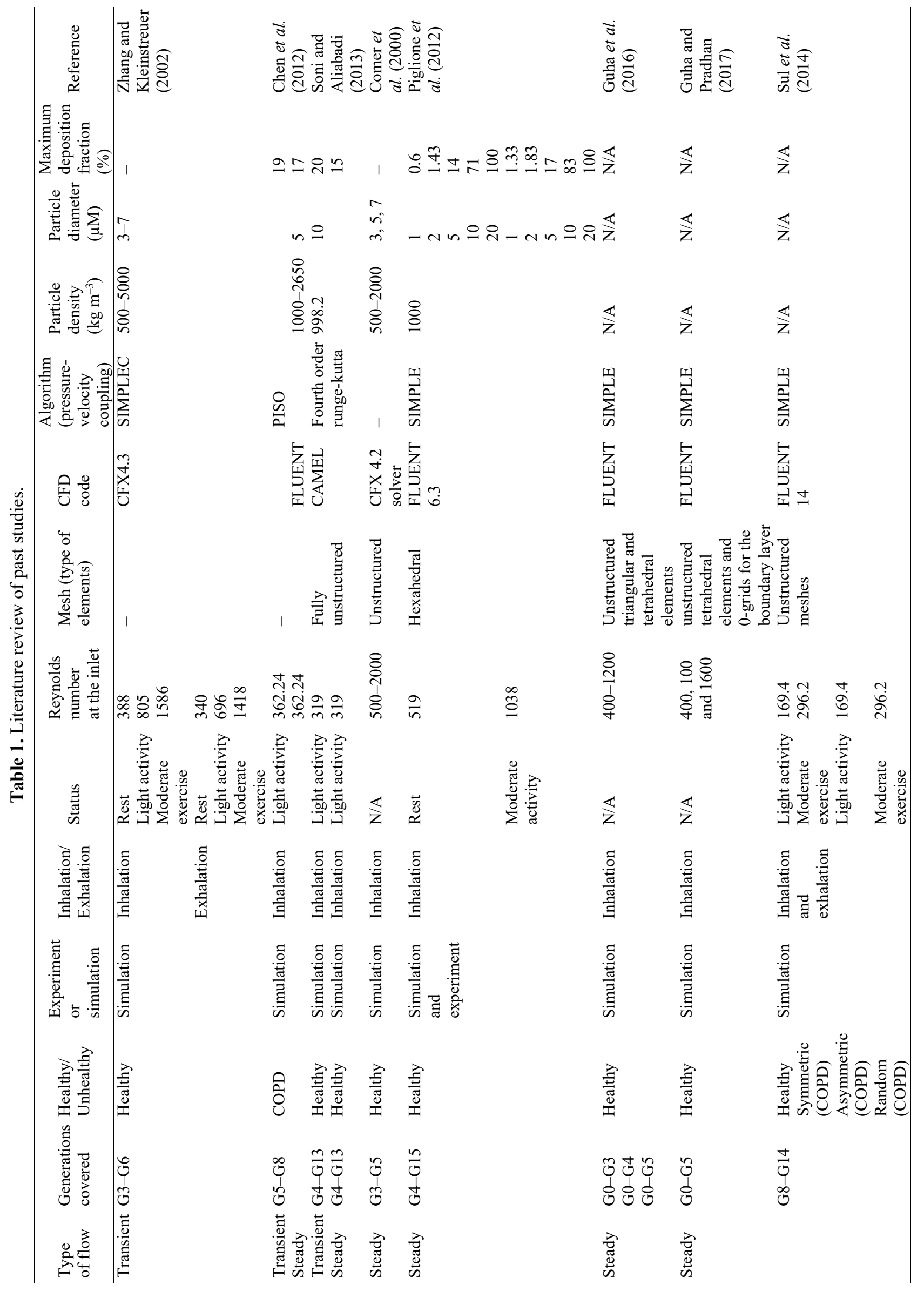




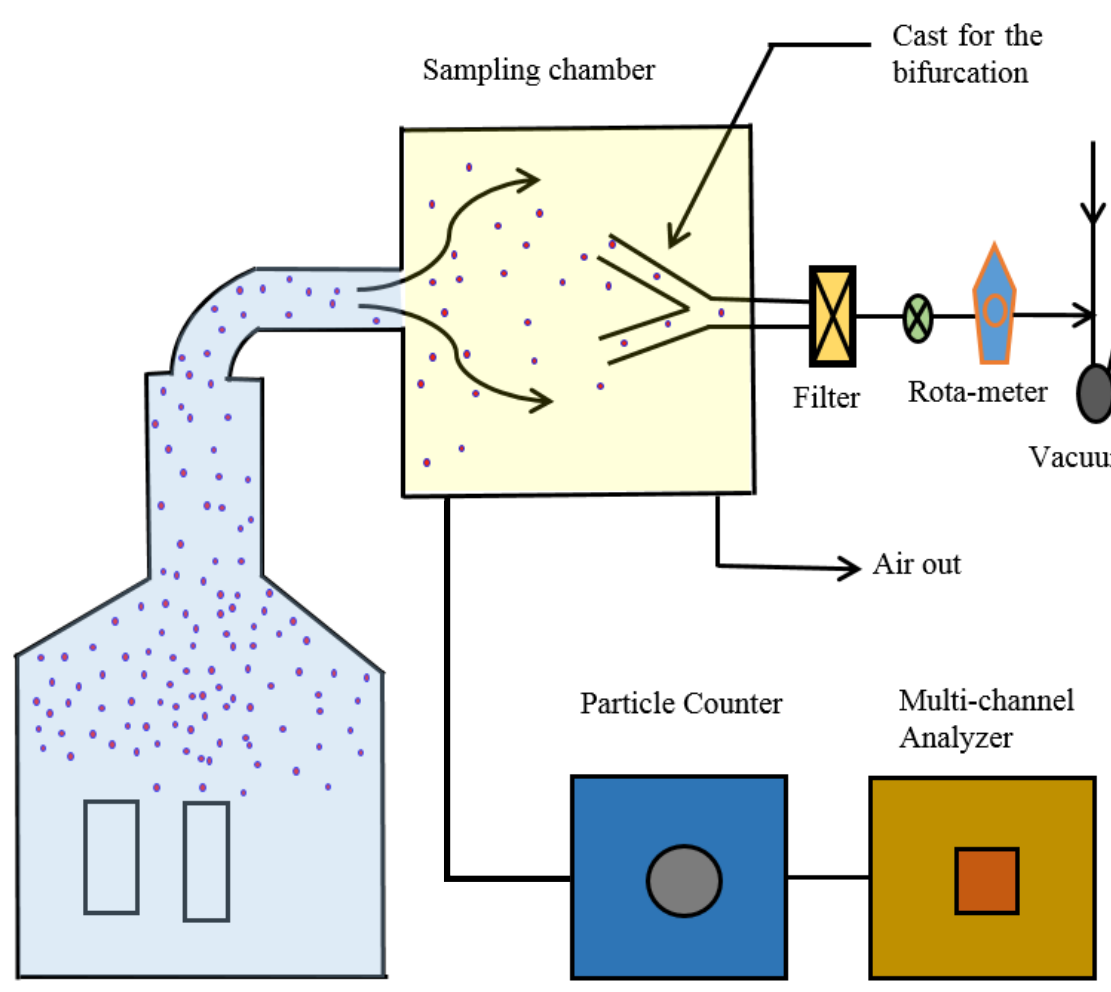

Fig. 4. Schematics of a typical arrangement for an in vitro experiment set-up on airflow dynamics and particle motion inside the human airways.

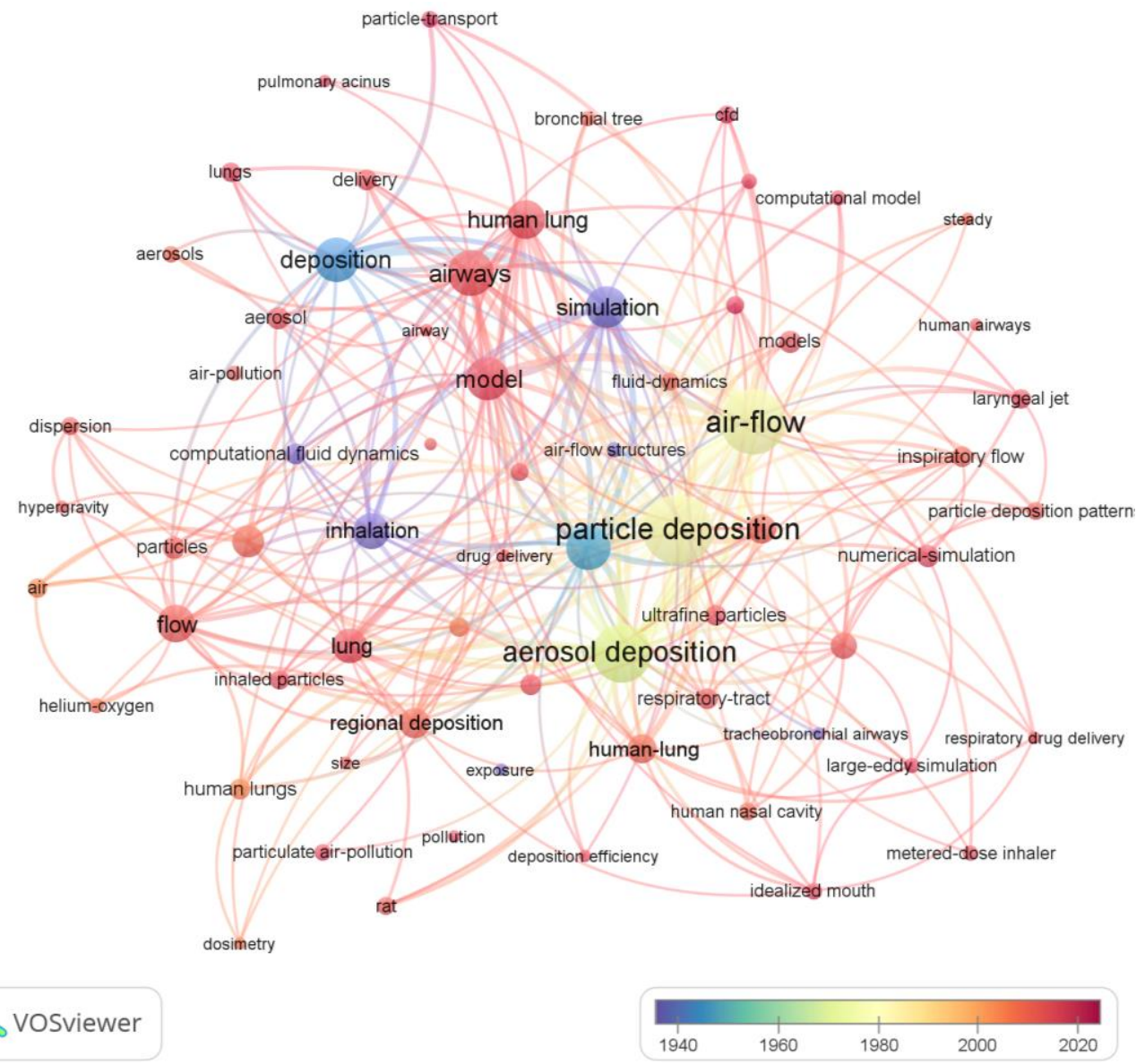

Fig. 5. VOSviewer map of the current state of research on aerosol motion and deposition in human airways. 


\section{FUNDAMENTALS OF NUMERICAL ANALYSIS}

Algebraic deposition models came before CFD methods, but their tendency to overestimate the effects of impaction on particle deposition led to the development and more extensive adoption of the CFD method which has higher accuracies. Mathematical dispersion models of bolus dispersion have also been applied in the prediction of particle motion and deposition in the human airways. The mathematical models have a drawback in the sense that they cannot account for information on particle trajectories and hence no available information on hotspots (Lambert et al., 2011). Only CFD methods will be covered under numerical analysis due to its extensive adoption as compared to other numerical methods for airflow simulation.

The main advantage of numerical analysis of airflow and particle motion inside the human airways is that it gives researchers the ability to study airflow phenomenon and particle motion in the respiratory system in ways that are experimentally impractical or incalculable. Additionally, it is an affordable and non-invasive method of gaining useful information on flow inside the human airways for medical or research purposes (Walters and Luke, 2010). With CFD tools, it is possible to carry out investigations using healthy and diseased human lung geometries on the resistance of airflow, distribution of mass flow rates, shear stress on the walls, complex secondary flow phenomena, and deposition patterns as well as efficiencies (Walters and Luke, 2010; Huang and Zhang, 2011; Tian et al., 2017).

\section{Geometrical Structures for the Human Airways}

Flow inside a confining geometry is strongly influenced by the geometric shape and as such creation of the human airway geometries is usually a vital step towards running a successful CFD simulation. A few software applications have been used before in the creation of human airway geometry, for instance, solid works and AutoCAD (Sul et al., 2014; Chen et al., 2018a). Important parameters in the creation of a physiologically accurate lung model include diameter, length, branching angle, and radius of the curvature. Carina regions are usually smoothened after lofting mother and daughter branches using the fillet options available in Computer-aided design applications. Information on the generations which are most likely to be affected by obstructions is obtained from bronchoscopy studies which are useful in choosing the obstructed generations in the creation of the solid geometries (Yanai et al., 1992). The extend of obstruction is chosen in a way that the volume reduction and airway surface reduction are consistent with histological studies conducted on obstructed airways for instance asthma and COPD (Zhang and Papadakis, 2010; Chen et al., 2012). Tools for 2D and 3D geometrical development are applied in the development of 2 dimensional and solid geometries which can either be human-specific or from the generalized human lung airway models discussed earlier.

\section{Governing Equations}

Several governing equations are applied for the numerical analysis of fluid flow and particle motion inside the human airways. Governing equations are also applied at the important sections of the control volume to represent the boundary conditions in different sections (Schreck and Mockros, 1970; Chen, 2002). Some of the governing equations for fluid flow, particle motion, drag coefficient, the velocity at the inlet, Reynolds number, and deposition efficiencies are summarized in Table 2. Fundamental steps for a CFD analysis are shown in Fig. 6.

\section{Mesh and Boundary Conditions}

Mesh generation is the process of subdividing a control volume into discrete geometric and topological grids. Meshes for the control volumes are usually generated using Gambit, ANSYS, or other mesh generating applications (Inthavong et al., 2010; Chen et al., 2011; Deng et al., 2018). The shape of the elements is important and it can be unstructured, hexahedral, tetrahedral, non-orthogonal blocks, and triangular prism (Rahimi-Gorji et al., 2015; Chen et al., 2018a). In a study of particle deposition inside a real human airway (G0-G2) by Rahimi-Gorji et al. (2015), the elements had unstructured tri/tetrahedral hybrid. In a study by Tena et al. (2015), tetrahedral meshes were used for the lung model due to their flexibility and ability to cope with complex solid geometries.

In an investigation comparing the effects of different boundary conditions, Nazridoust and Asgharian (2008) found out that the highest particle deposition was during unsteady flow boundary conditions imposed at the inlet of the control volume. Initial boundary conditions for the inlet and outlet are usually specified and can be based on either pressure or velocity. The velocity distribution at the inlet of any section of the human lungs can be uniform, symmetric parabolic, or skewed parabolic, depending on the position of the control volume in the lungs (Yang et al., 2006). For simulations concerning the upper section of the lungs, for instance, the oral cavity or nasal air passages, a uniform velocity distribution is sufficient (Moskal and Gradon, 2002). In a study by Gemci et al. (2008) a uniform velocity distribution of $2.896 \mathrm{~m} \mathrm{~s}^{-1}$ was imposed at the inlet. In a study of secondary flow phenomena, a non-uniform velocity distribution was imposed at the inlet of the control volume (Guha and Pradhan, 2017).

A no-slip boundary condition is usually imposed on the walls for airflow (Chen et al., 2012; Rahimi-Gorji et al., 2015), while a "trap upon impact" boundary condition is imposed for the aerosols due to the presence of mucus on the airway walls (Ma and Lutchen, 2009; Chen et al., 2018a). It is important to define a gauge static pressure at the outlet of the control volume and it is $1 \mathrm{~atm}$ for some studies (Ma and Lutchen, 2009; Guha and Pradhan, 2017; Chen et al., 2018a).

\section{Inhalation Curves}

Traditionally, the constant velocity at the inlets was assumed more so for in vitro experimental studies on airflow in the human lungs (Yeh and Schum, 1980; Chang and El Masry, 1982). Later, real inhalation curves at the inlets were imposed in carrying out CFD analysis (Zhang et al., 2002; Chen et al., 2012; Mutuku and Chen, 2018). Due to the similarity between real inhalation curves and sinewave curves, some studies have used velocity distribution at the 
Table 2. A summary of governing equations, boundary conditions, and dimensionless numbers

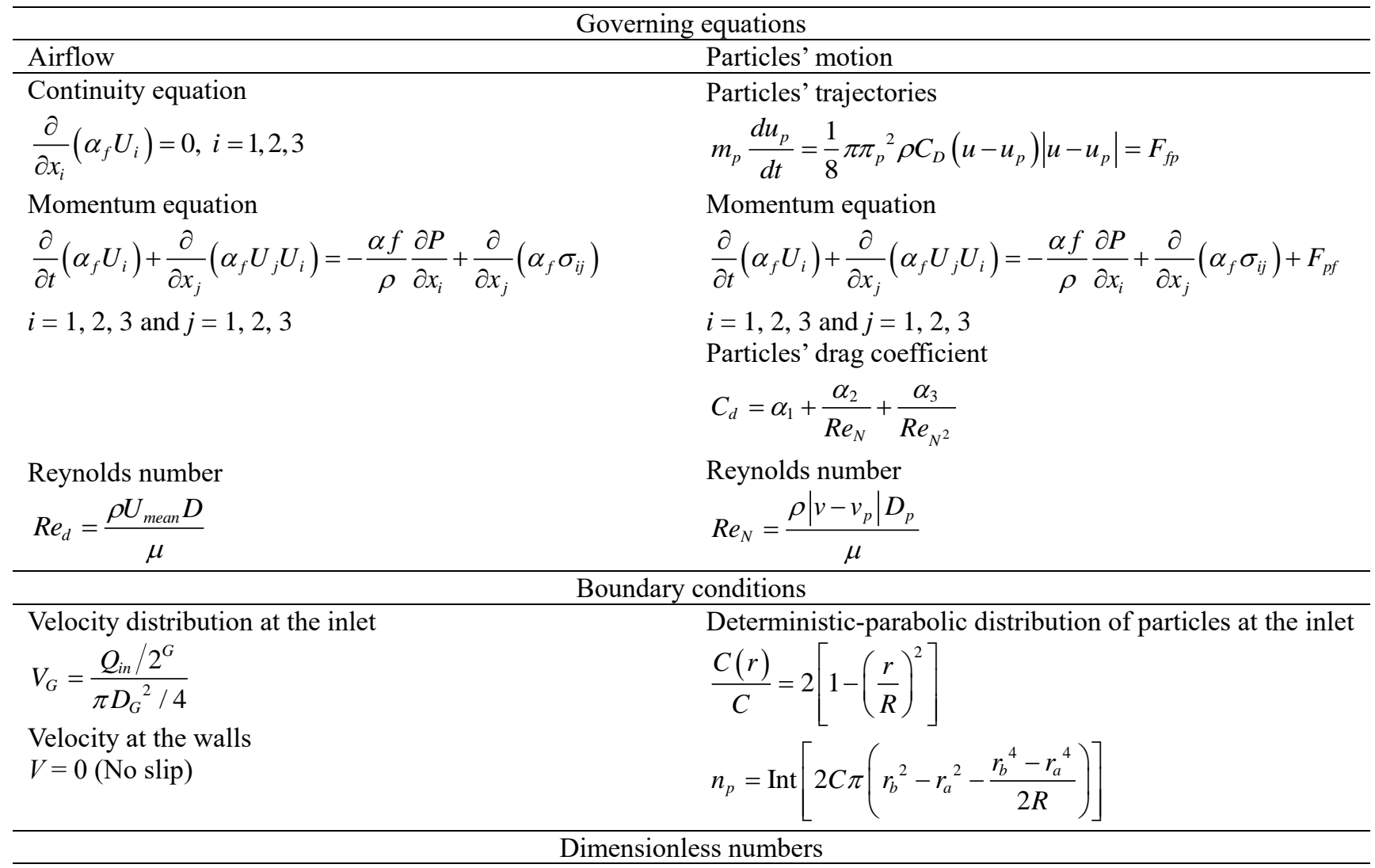

Reynolds number

$R e_{d}=\frac{\rho U_{\text {mean }} D}{\mu}$

Deposition fraction

$D F(\%)=\frac{\text { The number of particles deposited on a section of the walls }}{\text { The total number of particles entering that section of the wall }} \times 100$

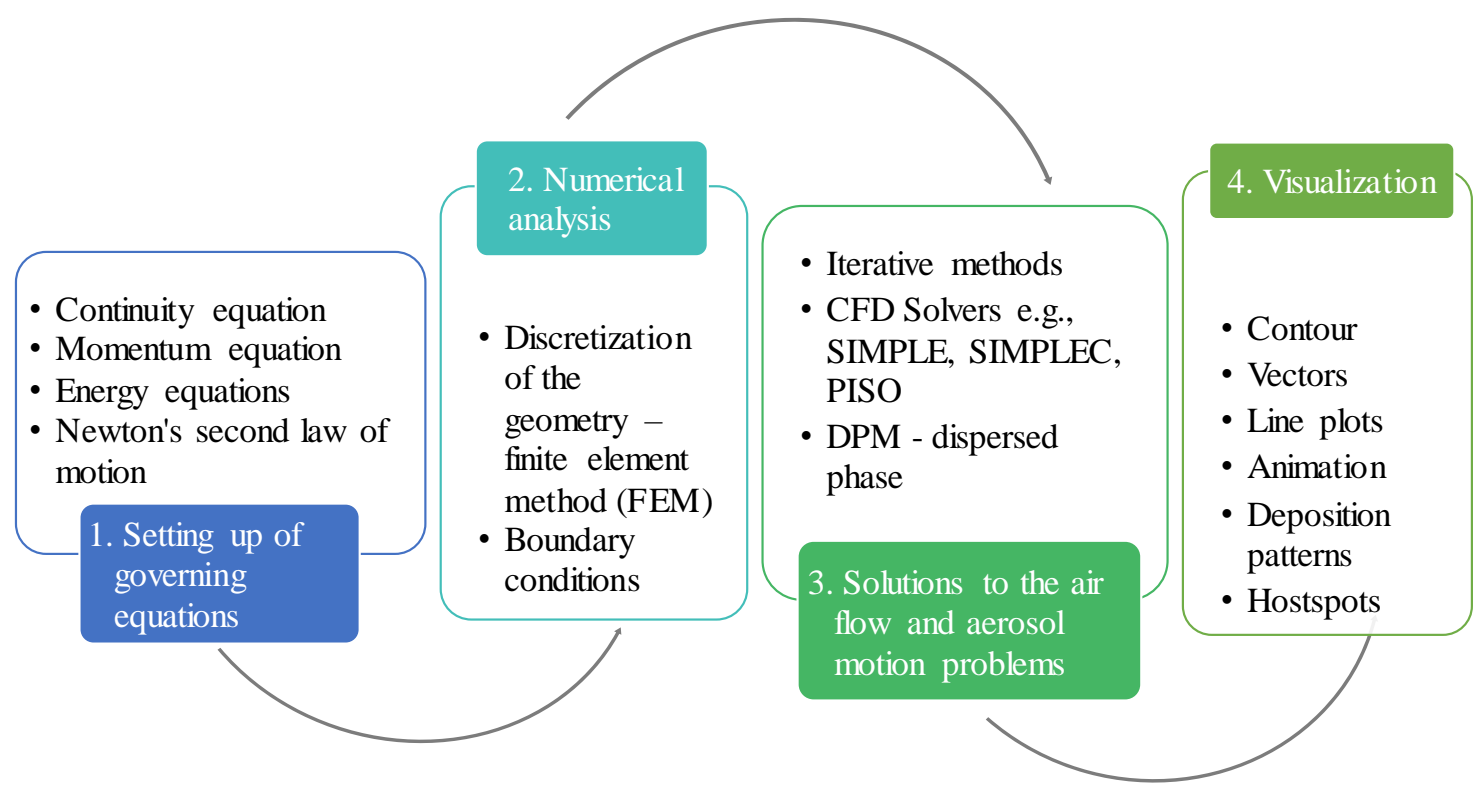

Fig. 6. Fundamental steps for developing a CFD and DPM solution for airflow and aerosol deposition in healthy and obstructed human airways. 
inlet in the form of a sinewave (Chen et al., 2018a). Typical real inhalation curves for rest, light activity, and moderate exercise, and their equivalent sinewave curves are shown in Fig. 7. Usually, a spirometry test is used to acquire the velocity variation at the inlet with time as in the case of a study by Tena et al. (2015). Many studies tend to differentiate the breathing statuses based on the level of the human activity and consequently the air mass flow rates during inhalation. Common breathing statuses include rest condition (sedentary), light activity, and moderate exercise. During normal breathing, the length and diameter variations in the large airways of the lungs are moderate and the rates of variation are insignificant compared to the axial airflow velocity, therefore the effect of wall movement is assumed to be very minimal (Hughes et al., 1972). Sometimes, volume flow rates are defined for localized investigations on the human airways, for instance, the case of Gemci et al. (2008) where $28.3 \mathrm{~L} \mathrm{~min}^{-3}$ was applied.

\section{Particle Size Distribution for Aerosols}

It is not enough to estimate particle dosage using particle number, mass, and surface area available for deposition only. In a combined experimental and numerical analysis
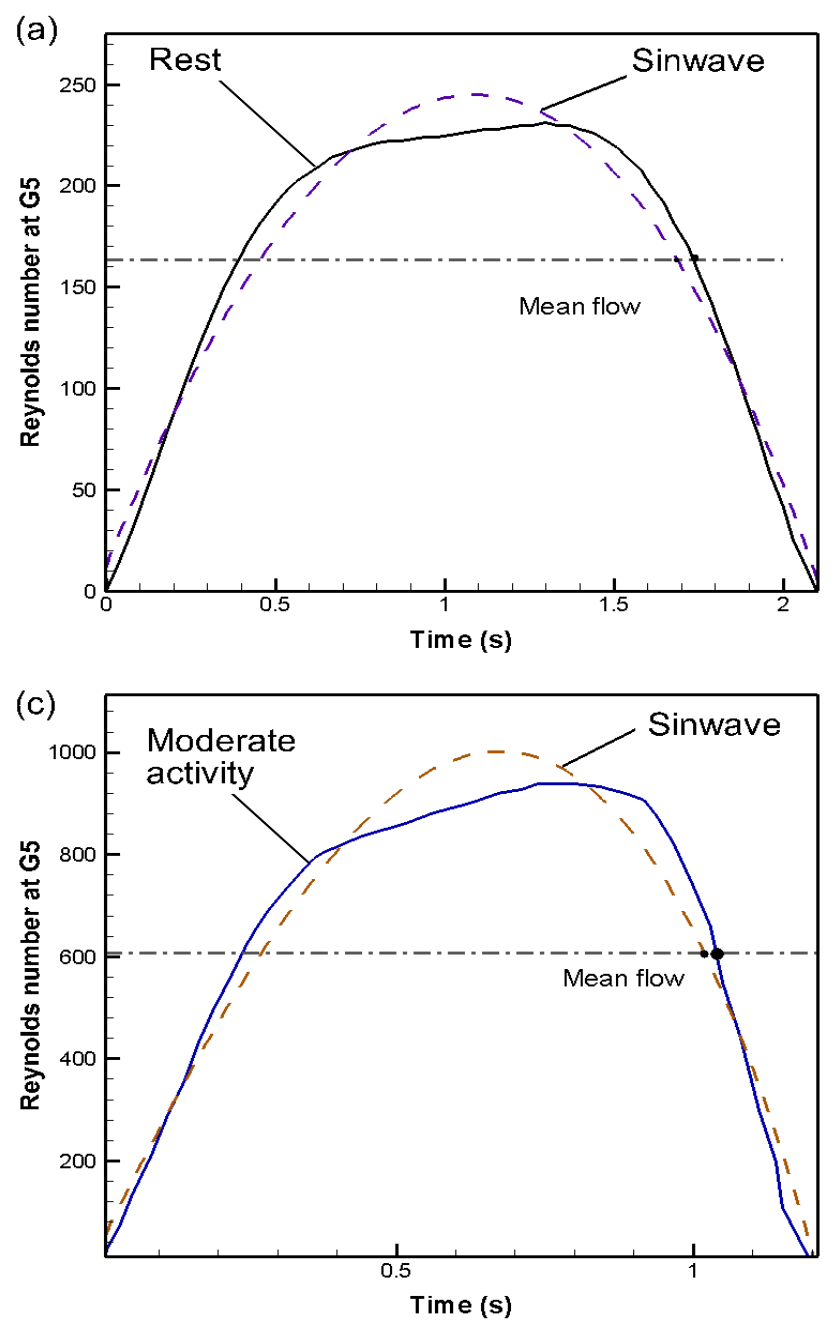

work by Tian et al. (2017), the importance of particle size distribution in estimating the dosimetry was established. Findings showed that deposition equations and particle size distribution were vital in the estimation of dosimetry for exposure risk assessment caused by nanoparticles.

In the CFD simulation for the deposition of $\mathrm{PM}_{2.5}$ in healthy and asthmatic human airways, the typical particle size distribution for $\mathrm{PM}_{2.5}$ in Taiwan was used (Chen et al., 2018a; Mutuku et al., 2020). Ideally, the distribution of particles at the inlet should be random, hence several studies have applied a random distribution of aerosols at the inlet (Zhang and Kleinstreuer, 2001; Russo et al., 2008; Chen et al., 2012; Chen et al., 2018b). A uniform particle distribution at the inlet has also been applied for investigations on aerosol deposition (Russo et al., 2008; Zierenberg et al., 2013; Kolanjiyil and Kleinstreuer, 2017). In a numerical analysis by Zhang and Kleinstreuer (2001), the effects of random-parabolic, random uniform, random-random, and deterministic-parabolic particle distributions at the inlet on the deposition patterns in a triple bifurcation were investigated. The findings proved that a satisfactory representation of the deposition patterns was achievable for both aerosol medicine and particulate matters if a parabolic-deterministic particle

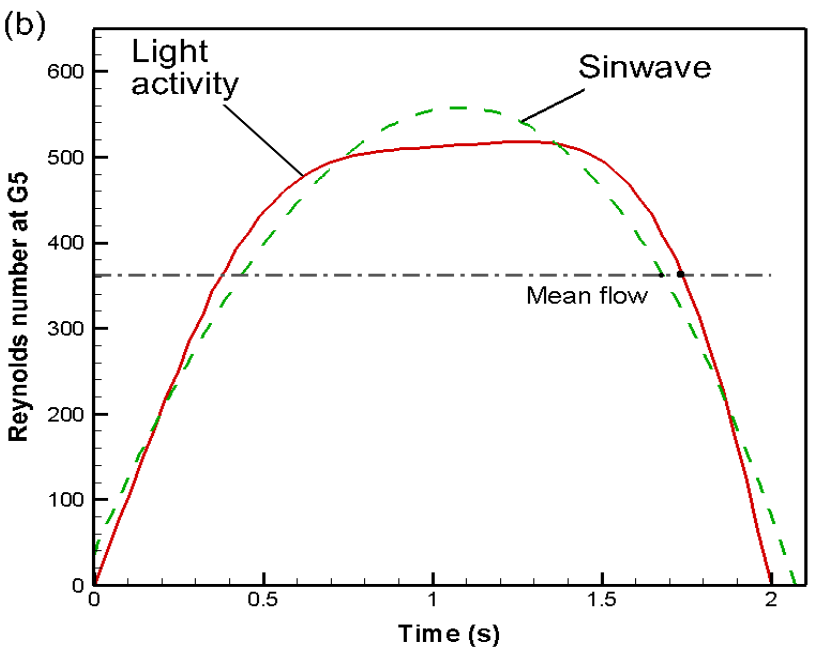

Fig. 7. Typical real inhalation curves and corresponding sinewaves for (a) rest, (b) light activity, and (c) moderate exercise. 
distribution was used at the inlet instead of a realistic random distribution. Consequently, some studies have used parabolicdeterministic particle distribution at the inlet to analyze the deposition efficiencies in a human lung bifurcation (Comer et al., 2000; Chen et al., 2018a).

\section{Solvers}

Numerical calculations for the Navier-stokes equations governing laminar airflow and newton's second law of motion governing particle motion in the lungs can be solved using CFD solvers and discrete phase models provided by applications such as ANSYS-fluent among others (Kelecy, 2008). Simulation of two-phase flow in the human airways usually applies one-way coupling, whereby the gas phase affects the solid phase only but there is no feedback from the dispersed phase (Comer et al., 2000; Luo et al., 2007; Rahimi-Gorji et al., 2015). The discrete phase model of CFD is activated by defining several parameters of the dispersed phase such as position in the control volume, velocity, diameter, temperature, mass flow, and time of injection (Rahimi-Gorji et al., 2015). The trajectory calculations use the initial location and parameters for the calculations.

Several CFD codes have been used in the simulation of fluid flow including CFX, Camel, FLUENT, and TASC flow 3D. CFX, which is a finite volume code and user-enhanced FORTRAN programs were applied at the beginning of this millennium to investigate airflow and aerosol motion in idealized lung models (Zhang and Kleinstreuer, 2002; Zhang et al., 2002). TASCflow, which is also a commercial CFD code with a standard $k-\varepsilon$ turbulence model was applied in a study by Stapleton et al. (2000) to compare the results of numerical analysis to that of in vivo experiment on aerosol deposition in the mouth and throat. Fluent CFD solver has two basic solver algorithms: density-based coupled solver (DBCS) and pressure-based coupled solver (PBCS). The former solves the equations of conservation of continuity, momentum, and energy in a coupled manner, while the latter solves the same equations in an uncoupled manner. Even though pressure-based algorithms are vigorous and resourceful, their applications in complex geometries are not applicable since their convergence rates are not satisfactory. The efficiency of the DBCS comes at a cost as it requires double the memory per element compared to PBCS since memory is needed for the coupled matrix equations (Kelecy, 2008). Other important parameters in the selection of a solver besides the memory requirements include time per iteration, iterations to converge, and time to convergence. DBCS is associated with a high computational cost. Consequently, PBCS is more popular for investigations of fluid flow inside the human airways (Kelecy, 2008). Some of the most common algorithms for airflow investigations in the human lungs are shown in Fig. 8(a), including the semi-implicit method for pressure-linked equations (SIMPLE), the semi-implicit method for pressure-linked equations-consistent (SIMPLEC), pressureimplicit with splitting of operators (PISO), and coupled.

\section{Airflow Dynamics in Human Airways}

Many parameters can be used to explain fluid flow in the human airways for instance; velocity distribution, jet flows, shear stress, and stagnation and recirculation zones, on the walls (Zhang et al., 2002; Kleinstreuer and Zhang, 2010; Chen et al., 2012).

\section{Airflow Velocity Distribution and Pressure Drop}

Airflow fields are important in determining the deposition patterns of particulate matter in the human airways. Airflow velocity distribution also affects pressure distribution since the two are closely linked (Luo et al., 2007; Kang et al., 2011). The airflow distribution is an important indicator of sections of the lungs suffering from inadequate ventilation as a result of lung obstructive diseases. The velocity distribution inside the control volume is responsible for the formation of stagnation and recirculation zones as well as jet flow phenomena in constrictions (Chen et al., 2012; Chen et al., 2018a). Flow phenomena resulting from velocity distributions greatly affect particle deposition patterns in both health and deformed human airways.

In a study by Gemci et al. (2008), a static pressure drop of $50 \mathrm{~Pa}$ was associated with a volumetric flow rate of 28.3 $\mathrm{L} \mathrm{min}^{-3}$ between G0 and G17. The further pressure drop across the entire Weibel's geometry was determined to be $60 \mathrm{~Pa}$ (Pedley, 1977). This had been previously investigated through an experiment by Hyatt and Wilcon (1963), whereby the pressure drop in the entire human lung was found to be $75 \mathrm{~Pa}$. In a study by Qi et al. (2014), patients suffering from left pulmonary artery sling (LPAS) were found to have a pressure drop in the two bronchi ranging between 78.9914.5 $\mathrm{Pa}$, as compared to a usual pressure drop of $0.7 \mathrm{~Pa}$ in a healthy individual.

\section{Jets, Recirculation Zones and Secondary Flow Phenomena}

Jets tend to form in constriction according to the results from most CFD simulations and comparisons of healthy and obstructed airways. Boundary layer separation in the regions near the constrictions led to the recirculating phenomenon (Sul et al., 2014). Vorticity in obstructed airways can be obtained by the curl of the velocity field. In obstructed airways, the vorticity is usually on the ranges of 100-fold higher as compared to a normal airway.

\section{Shear Stresses}

Amplified wall shear stresses in human airways are responsible for inducing the disease defense mechanism by activating the release of Adenosine triphosphate (ATP) as well as the release of intracellular calcium (Fisher et al., 2001; Garcia et al., 2006; Sidhaye et al., 2008). It has also been previously proven that low-level shear stress bears an inverse relationship with the permeability of epithelial cells (Sidhaye et al., 2008), while excessive wall shear stress can cause epithelial damage, especially in the re-opening a previously collapsed airway (Bilek et al., 2003). Therefore, understanding shear stress distribution can explain the healing process of wounds in the epithelial lining of the lungs (Suh and Park, 2018).

\section{Models for Turbulent Flows}

Flow in the human lungs is largely laminar and as such most of the CFD investigations in which are based on central 
(a)

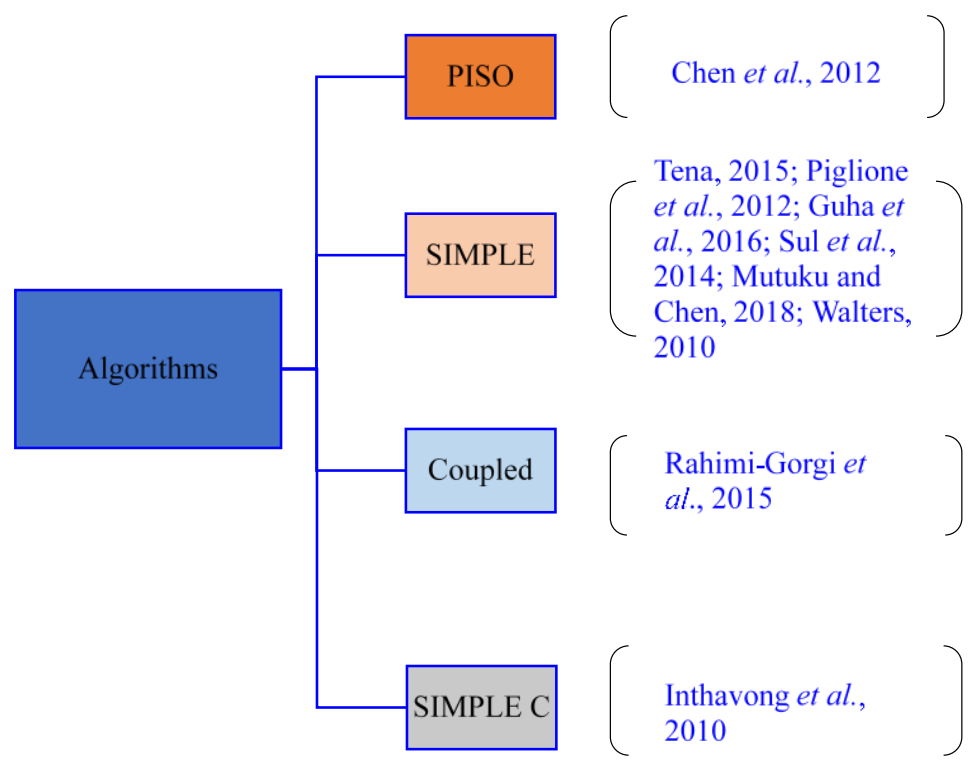

(b)

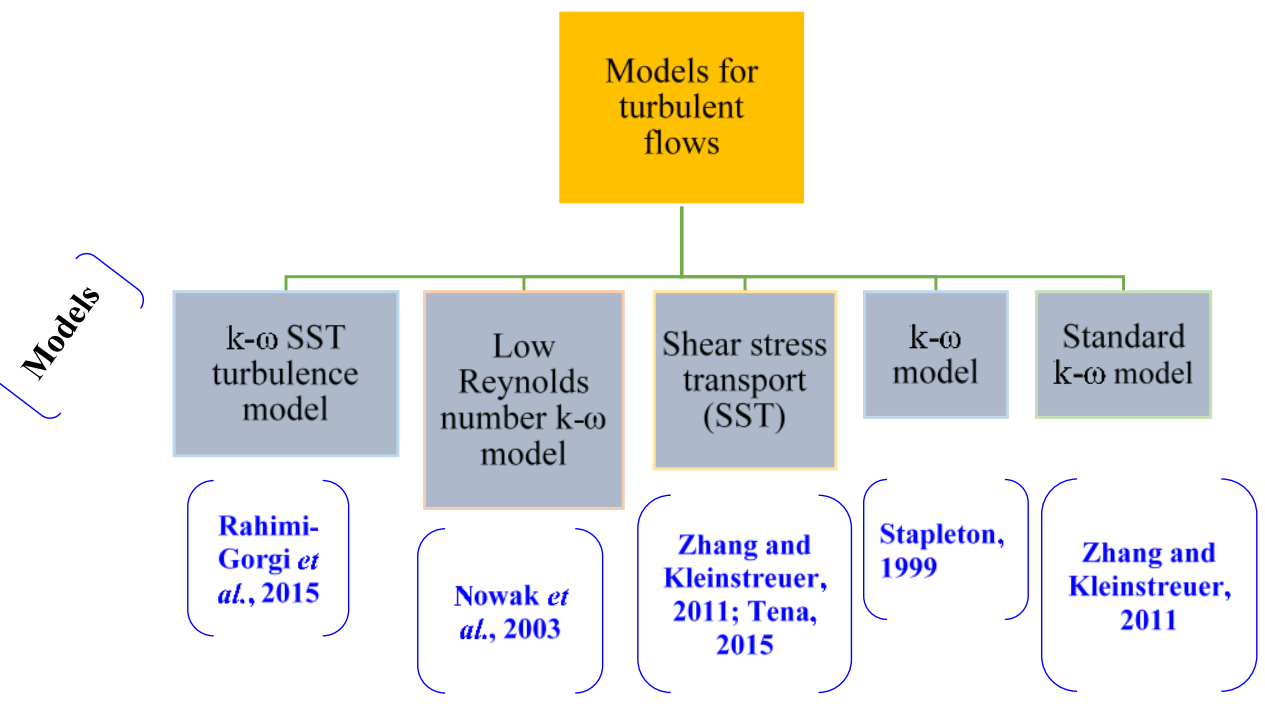

Fig. 8. (a) Common algorithms applied in CFD models to evaluate particle motion and airflow dynamics (b) Models for turbulent flows in the human airways.

and lower regions do not require turbulent flow models (Chalupa et al., 2004; Zhang and Papadakis, 2010; Chen et al., 2012). However, different models (turbulent) are applied in investigations of airflow in the upper region and part of the central region of the human airway (Inthavong et al., 2010; Zhang and Kleinstreuer, 2011; Rahimi-Gorji et al., 2015). The upper section of the human lung experiences laminar-turbulent transitional regions as air progresses from the oral cavity and larynx to the trachea and bronchioles (Kolanjiyil and Kleinstreuer, 2017). As such modeling airflow through these sections of the respiratory system requires models that can handle the turbulent flow. Usually, Reynolds averaged Navier Stokes (RANS) are combined with Randomwalk eddy interaction models (EIMs) to effectively cover the effect of turbulent flow on particle motion in the upper sections of the human airways. Large-eddy simulation (LES) can also effectively account for the effect of turbulent flow on the particle's motion. Recent developments show that
LES is better at simulating turbulent flow as compared to a combination of RANS and EIMs. This is because RANS turbulence models tend to average out the turbulent effects and hence may not capture fully the resultants effects of recirculation on the particle motion (Lambert et al., 2011).

Fluent applies a finite volume approach in obtaining the numerical solutions to Navier-Stokes and continuity equations in a control volume with the appropriate geometry and boundary conditions. For the upper section of the respiratory system that is the oro-nasal cavity, trachea, and bronchus, airflow is usually turbulent. Therefore, turbulence models and LES are applied (Gemci et al., 2008). LES models can provide instantaneous velocity fluctuations and vortex structures, whereas RANs cannot. However, LES models are 100 times more costly in terms of computational time when compared to RANS models. Direct numerical simulation (DNS) is another alternative approach but it is limited to certain types of control volumes. It also requires excessively 
huge computational resources (Zhang and Kleinstreuer, 2011). Turbulent models are useful for modeling airflow in the upper sections of the respiratory system. This is because, in these regions, for instance, the throat, airflow experiences local area reductions, which increases the Reynolds number and causes turbulent flow. Thereafter, due to the subsequent increase in effective cross-sectional area, the Reynolds number decreases and the flow gets re-laminarized. Due to the above-mentioned limitations of both LES and DNS, RANS finds preference amongst researchers in predicting airflow behavior.

In an investigation by Zhang and Kleinstreuer (2011), insignificant differences of less than $0.5 \%$ in DEs were found in the performance of LES, LRN k- $\omega$ and SST transition. This finding was made while doing a numerical analysis of the deposition efficiencies for nanoparticles $(1 \mathrm{~nm}-50 \mathrm{~nm})$ during the transition to turbulent flow in the oral airways model. The SST transition model proved better results in the prediction of kinetic energy profiles while the LES model could provide information on instantaneous velocity fluctuations.

The standard $\mathrm{k}-\omega$ turbulence model is more effective for predictions near the wall region as compared to the $k-\omega$, but it performs poorly in the far-field. On the other hand, the SST $k-\omega$ combines a bit of both and is, therefore, more favorable for turbulent and transitional flows (Tena et al., 2015). The SST $k-\omega$ equations are expressed as

$$
\begin{aligned}
& \frac{\partial}{\partial t}(\rho k)+\frac{\partial}{\partial x_{i}}\left(\rho k u_{i}\right)=\frac{\partial}{\partial x_{i}}\left(\Gamma_{k} \frac{\partial k}{\partial x_{j}}\right)+\tilde{G}_{k}-Y_{k}+S_{k} \\
& \frac{\partial}{\partial t}(\rho \omega)+\frac{\partial}{\partial x_{i}}\left(\rho \omega u_{i}\right)=\frac{\partial}{\partial x_{j}}\left(\Gamma_{\omega} \frac{\partial \omega}{\partial x_{j}}\right)+\tilde{G}_{\omega}-Y_{\omega}+D_{\omega}+S_{\omega}
\end{aligned}
$$

where $\rho$ is the air density, $k$ represents the turbulence kinetic energy, $\omega$ represents the specific dissipation rate. $G_{k}$ and $G_{\omega}$ refer to the generation of turbulence kinetic energy because of mean velocity gradients and the generation of $\omega$ respectively. $\Gamma_{k}$ and $\Gamma_{\omega}$ are the effective diffusivities of $k$ and $\omega$, respectively while $Y_{k}$ and $Y_{\omega}$ are the dissipation of $k$ and $\omega$, respectively, due to turbulence. Lastly, $D_{\omega}$ is the cross-diffusion term, and $S_{k}$ and $S_{\omega}$ are user-defined source terms. A summary of the available turbulent models is shown in Fig. 8(b).

\section{MECHANISMS FOR AEROSOL DEPOSITION AND CLEARANCE}

The human airways are usually lined with mucus, which helps to trap suspended particulate matters in the inhaled air mass. It thus follows that a trap upon impact is usually the boundary condition imposed on the walls of the airways during the numerical analysis of two-phase flow inside the human airways. From the analysis of particle deposition, important information includes deposition patterns, hot spots, and deposition efficiencies.

\section{Mechanisms of Deposition}

There are several mechanisms through which inhaled aerosols deposit on the airways' walls. The dominance of these mechanisms of deposition varies as the particles advance from the oral cavity, through the upper, central, lower section of the human lungs, and later into the alveolar region. There are 5 main deposition mechanisms, including turbulent mixing, inertial impaction, gravitational sedimentation, Brownian motion, and electrostatic precipitation (Finlay and Martin, 2008; Darquenne, 2012). A summary of the mechanisms of aerosol deposition and their respective regions of dominance is shown in Table 3.

\section{Turbulent Mixing}

Unlike the central and lower sections of the human airways where the flow is usually laminar, the upper section of the lungs is associated with turbulent airflow. Rapid changes in both the magnitude and direction of flow by the air-aerosol mixture lead to an eventual impaction on the airway walls (Darquenne, 2012). Furthermore, branch curvature as air progresses from the parent bifurcation to the child branch

\begin{tabular}{|c|c|c|}
\hline Region & $\begin{array}{l}\text { Dominant aerosol deposition } \\
\text { mechanism }\end{array}$ & Dominant aerosol clearance mechanism \\
\hline $\begin{array}{l}\text { Extra-thoracic region } \\
\text { (Oro-nasal passages) }\end{array}$ & $\begin{array}{l}\text { Deposition by } \\
\text { 1. Turbulent flow } \\
\text { 2. Inertial impaction }\end{array}$ & $\begin{array}{l}\text { Mechanical clearance (sneezing, coughing or } \\
\text { swallowing of the inhaled aerosols) }\end{array}$ \\
\hline $\begin{array}{l}\text { Tracheal-bronchial region } \\
\text { (TB) }\end{array}$ & $\begin{array}{l}\text { Deposition by } \\
\text { 1. Turbulent mixing } \\
\text { 2. Inertial impaction }\end{array}$ & $\begin{array}{l}\text { Mucociliary clearance (for insoluble particles in the TB } \\
\text { region. ( } 24 \text { hours) - operates like an escalator driving } \\
\text { aerosol loaded mucus from the TB region to the larynx } \\
\text { where mechanical clearance mechanism takes over. }\end{array}$ \\
\hline Bronchiolar region & $\begin{array}{l}\text { Deposition by } \\
\text { 1. Inertial impaction } \\
\text { 2. Diffusion }\end{array}$ & Translocation \\
\hline Acinar region (G16-23) & $\begin{array}{l}\text { Deposition by } \\
\text { 1. Diffusion } \\
\text { 2.Gravitational sedimentation } \\
\text { 3.Electrostatic deposition }\end{array}$ & $\begin{array}{l}\text { Translocation } \\
\text { Microphage arbitrated clearance where white blood cells } \\
\text { engulf and relocate the particles towards the bronchiolar } \\
\text { region, circulatory system, or the lymphatic region. }\end{array}$ \\
\hline
\end{tabular}

Table 3. Dominant aerosol deposition mechanisms and lung clearance mechanisms at different sections of the human airway. 
induces lateral convective motions (Hammersley and Olson, 1992). This convective motion initially purposed to ensure the mixing of the inhaled gases also causes particle deposition on the airway walls. Turbulent mixing has been proven through experiments to affect the local deposition in G3-G5 by influencing the initial velocity and particle motion (Longest and Vinchurkar, 2007).

\section{Inertial Impaction}

This mechanism greatly affects particles whose diameter exceeds $5 \mu \mathrm{m}$. This is because heavier particles are incapable of changing the direction of motion with a sudden change in the direction of fluid flow. This results in a deviation from the streamlines of flow and eventual impaction on the airways' walls (Darquenne, 2012). The property of deviation from the streamlines of flow for two-phase flow is best defined using the stokes number which is expressed by;

$S t=\frac{\rho_{p} d_{p}^{2} u}{18 \mu d}$

where $S t$ is the Stokes number, $d_{p}$ and $\rho_{p}$ are the diameter and density of the suspended particles, respectively, $u$ and $\mu$ are the average velocity and dynamic viscosity of the gas phase, respectively, and $d$ is the diameter of the airway. Overall, deposition by inertial impaction increases with an increase in the Stokes number. In an experimental study by Yeh and Schum (1980), the formula for impaction deposition probability was summarized as follows;

$P_{I}=1-\frac{2}{\pi} \cos ^{-1}(\theta-S t)+\frac{1}{\pi} \sin \left\{2 \cos ^{-1}(\theta \times S t)\right\} V_{s}=\frac{\rho_{p} d_{p}^{2}}{18 \mu} g$

for $\theta \times S t<1$

$P_{I}=1$ for $\theta \times S t>1$

where $P_{I}$ is the impaction deposition probability and $\theta$ is the angle of the bend in radians.

\section{Gravitational Sedimentation}

This mechanism of deposition is absent in upper airways but strongly present in central and lower airways. This is because a shorter distance exists between the particles and the airway walls for central and lower airways (Darquenne, 2012). This property is best represented by the terminal settling velocity of the particles, which can be expressed as;

$V_{s}=\frac{\rho_{p} d_{p}^{2}}{18 \mu} g$

where $g$ is the acceleration due to gravitational force. The most important factors during deposition by sedimentation are particle size and particle residence time in the airways and alveoli. This mechanism of deposition mostly affects particles whose diameter ranges between 1 and $8 \mu \mathrm{m}$.

\section{Brownian Diffusion}

This mechanism results from the random motion of the particles as a result of collisions with the gas molecules. It happens where the velocity of airflow is low, especially in the alveoli region (Darquenne, 2012). Deposition by this mechanism occurs predominantly for particles with a diameter of smaller than $0.5 \mu \mathrm{m}$, and is usually proportional to the Brownian diffusion coefficient which can be expressed as;

$D_{B}=\frac{c k T}{3 \pi \mu d_{p}}$

where $D_{B}, c, k$, and $T$ represent the deposition by Brownian motion, Cunningham's correction factor, Boltzmann's constant, and the absolute temperature, respectively. The Cunningham's correction factor accounts for the reduced air resistance as a result of slippage when the particles' diameters approach the mean free paths of the gas molecules.

After experimentation, Yeh and Schum (1980) reported that deposition by diffusion was different for both laminar flow and turbulent flow. For laminar flow, the probability of deposition by diffusion can be expressed as;

$$
\begin{aligned}
P_{D}= & 1-0.819 e^{-7.315 x}-0.0976 e^{-44.63 x}-0.0325 e^{114 x} \\
& -0.0509 e^{-79.31 x^{2 / 3}} \\
x & =\frac{L D}{2 R^{2} \bar{v}}
\end{aligned}
$$

where $P_{D}$ is the probability of deposition by diffusion, $D$ is the diffusion coefficient of the particles, $R$ is the radius of the airway's bifurcation, $\bar{v}$ is the mean flow velocity, and $L$ is the length of the bifurcation. For turbulent flow, it can be expressed as;

$P_{D}=\frac{2 \sqrt{D t}}{R}\left(1-\frac{2 \sqrt{D t}}{9 R}+\ldots\right)=2.828 x^{1 / 2}\left(1-0.314 x^{1 / 2}+\ldots\right)$

where $t$ represents the time needed for the flow to cover the bifurcation's length, i.e., $L / \bar{v}$

For a pause,

$P_{D}^{p}=1-\exp \left(-\frac{5.784 K T C_{t}}{6 \pi \mu r_{p} R^{2}}\right)$

where $t$ is the length of time in the pause, $K$ is the Boltzman constant, $T$ is the temperature in $K, C$ is the Cunningham slip correction factor, $r_{p}$ is the particle's radius, $\mu$ is the fluid's viscosity, and the superscript $p$ represents pause (Yeh and Schum, 1980).

\section{Electrostatic Precipitation}

This process is only effective for particles in possession of charges. Charges are induced at the walls of the airways by charged particles in close proximity. As a result, the walls attract electrically charged particles leading to deposition (Darquenne, 2012). 


\section{Interception}

The efficiency of this mechanism of deposition is dependent on the shape and hygroscopicity of the particles, whereby elongated and hygroscopic particles deposit more easily. This mechanism involves a particle coming into contact with the airway walls while still following a streamline of flow (Darquenne, 2012). Deposition by interception decreases significantly for particles with a spherical shape.

\section{Factors Influencing Particle Deposition}

Particle deposition efficiencies and patterns are dependent on several factors including, the geometry of the tracheobronchial model, inhalation status, and chemical and physical properties of the particles.

Due to the bifurcating nature of the human airways, the inhalation segment of the breathing cycle provides a larger surface area for particle deposition through impaction as compared to the exhalation phase. Consequently, the deposition efficiencies during the inhalation phase tend to exceed those of the exhalation phase for the same local stokes number (Zhang et al., 2002). Additionally, the curved walls of the bifurcating geometries provide surface areas for particle interception as the particles are driven onto the walls by the induced dean vortices (Chen et al., 2018a; Mutuku and Chen, 2018). In the investigation of Guha and Pradhan (2017), new secondary flow structures including dean vortices and antidean vortices were found to develop in the curved human airway generations.

The physical parameters of the particles also have an impact on the deposition efficiencies. Specifically, the diameter of inhaled aerosols is directly linked to the Stokes number of the particles for a constant density. Previous research has shown that deposition efficiencies for aerosols increase with an increase in their Stokes numbers since impaction is the main deposition mechanism (Cheng et al., 1999; Zhang et $a l .$, 2002). Usually, in performing numerical analysis, the particles are assumed to have a spherical shape and hence their Stokes number tends to increase with an increase in their diameters. In a study by Cheng et al. (1999), the deposition efficiency was found to correlate to the stokes number of the particles by the following equation.

$\eta=1-\exp (-\alpha S t)$

where $\eta$ is the deposition efficiency, $S t$ is the Stokes number, and $\alpha$ is the best fit parameter whereby it was $6.66 \pm 0.418$ (SEM) and $\mathrm{r}^{2}=0.976$ (Cheng et al., 1999).

The deposition of particles on the airway walls is greatly influenced by their solubility in water. The particles which are soluble in water tend to deposit more easily. This is because the moisture content inside the human lungs increases their weight and hence their chances of depositing through inertial impaction (Ferron et al., 1989). The shapes of the aerosols have been shown to affect their deposition efficiencies in previous researches. For instance, elongated aerosols can easily deposit through interception.

The presence of deformities in the lung's geometry, for instance, the presence of tumors, asthma, and COPD, which usually result in obstructions, leads to local deposition rated to increase by $\times 10$ to $\times 100$ (Longest et al., 2006). In a study on the effect of COPD in human airways, Chen et al. (2012) found a hotspot for the deposition of $6 \mu \mathrm{m}$ particles at the constriction (G6) in a geometry consisting of G5-G8. Furthermore, the deposition efficiencies of $0.075,0.15,0.3$, and $0.6 \mu \mathrm{m}$ particulate matters in an asthmatic human airway were found to exceed that in a healthy human airway by $1.19 \%, 2.5 \%, 14.3 \%$, and $25 \%$, respectively, during a moderate exercise (Chen et al., 2018a). These elevated deposition efficiencies lead to aggravated risks due to inhalation of toxic aerosols.

Enhanced condensational growth (ECG) is a recently developed method of pharmaceutical aerosol delivery, aimed at increasing their deposition efficiencies. Usually in this approach, a stream of medicinal nanoparticles is injected at the mouth region followed by an air stream that is supersaturated (Kulmala et al., 2004; Phalen et al., 2010; Tian et al., 2011). This is done to minimize depositional losses at the extrathoracic region and encourage deeper penetration of the aerosols into the central and lower section of the human airways. It is believed that aerosols with a diameter of 2-4 $\mu \mathrm{m}$ have almost perfect retention inside the lungs.

\section{Methods of Quantifying Deposition}

There are two ways of quantifying deposition. The use of DEs is the most commonly used method of quantifying the deposition of aerosols in the human airways either through in vitro experiments or numerical analysis. Deposition enhancement factors (DEFs) are used to quantify the deposition in a certain zone as compared to deposition in an entire region of consideration. DEFs for microns exceed those of nanoparticles. Specifically, in a study by Guzman (2020), the DEFs for $40 \mu \mathrm{m}$ particles were found to exceed those of $40 \mathrm{~nm}$ particles.

Establishing the position of hotspots is an important aspect of studies on particle deposition. Hotspots are localized regions of high deposition. This is important because it makes it possible to quantify particle dissolution, particle clearance, and the uptake of the dissolved chemical compositions into the epithelial layer. Hotspots have been associated with lung cancer and tumors. A $30 \%$ contraction in the upper tracheobronchial airways due to asthma could increase the DEs by 10-100 times. Disproportionate amounts of aerosols are known to enter the left bronchi, despite a higher mass flow of air going into the right bronchi (Lambert et al., 2011).

\section{Lung Clearance Mechanisms}

The lung structure is designed to allow the mixing of air as it flows towards the alveolar region. However, this leads to the impaction of the suspended particles on the walls as air progresses into the acinar region (Tsuda et al., 2008). The lung has several clearance mechanisms that help to rid the airway walls of deposited particles. The first clearance mechanism is mechanical clearance and it takes the form of coughing, sneezing, or swallowing. This mechanism is dominant in the upper section of the airways, specifically the oro-nasal region (Hussain et al., 2011). Mucociliary clearance is the second mechanism and involves the propulsion of aerosol filled mucus from the middle section of the human 
lungs towards the oro-nasal region so that they can be ejected out of the respiratory system through the mechanical clearance. The third clearance mechanism involves the macrophages which engulf the aerosols and get into the circulatory system or the lymphatic system. This clearance mechanism is dominant in the alveolar region of the human airways (Hussain et al., 2011). A summary of the lung's clearance mechanism and their respective region of dominance is shown in Table 3.

\section{COVID-19 AND THE RESPIRATORY SYSTEM}

\section{Effects of COVID-19 to Human Lungs}

Lungs are very delicate and, consequently, get easily damaged. The latest global pandemic of COVID-19 is a classic case of diseases which is easily transmitted through respiratory droplets and can be fatal or lead to permanent lung damage. In a recent study of Olds and Kabbani (2020), exposure to nicotine through smoking was shown to propel individuals to higher risk from COVID-19 due to the impact on the putative receptor for the virus (ACE2). Older people and those with weakened immunity systems were more susceptible to the adverse effects caused by COVID-19. COVID-19 patients suffered from a serious inflammation of the lungs after which the alveoli were filled with water, pus, and debris from epithelial cells destroyed by the immune system in the process of fighting the infection (Yoon et al., 2020).

Results from CT scans showed that the lungs of patients had lesions whose density could be hardly depicted using conventional radiography. Consequently, a routine exercise of obtaining high-resolution chest CT examination was seen to be key in the diagnosis of the disease (Agostini et al., 2020; Zhao et al., 2020). The abnormalities associated with COVID-19 according to a study by Yoon et al. (2020). In a study by Li et al. (2020a), pathological alterations caused by the disease include lung edema and acute lung injury (ALI) which eventually caused acute respiratory distress syndrome (ARDS). ALI came as a result of the activation of the epithelial and endothelial cells and the consequent overproduction of proinflammatory cytokines. As the severity of COVID-19 disease increases, patients have been shown to suffer multiple organ failure and eventual death.

\section{Role of Bioaerosols in COVID-19 Transmission, Possible Control Strategies and Future Challenges}

The most familiar mode of transmission of SARS-CoV-2 virus involves a healthy individual coming into contact with surfaces that have been contaminated by infected aerosols. As such, a $2 \mathrm{~m}$ distance has been recommended among persons as a form of social distancing to curb the spread of the disease. This social distancing is aimed at preventing bioaerosols with SARS-CoV-2 from reaching the respiratory system of healthy individuals (Guzman, 2020).

Even though earlier investigations ruled out the airborne transmission in the role of the spread of SARS-CoV-2, recent investigations showed that this might not be the case. The diameter of bioaerosols released from individuals infected with COVID-19 during breathing, talking, sneezing, and coughing can range between 0.6-125 $\mu \mathrm{m}$ (Guzman, 2020). In the investigation by Asadi et al. (2020), particles with a diameter of about $1 \mu \mathrm{m}$ were found to be released during normal breathing and speech. This size was adequate to carry SARS-CoV-2 viruses which have a diameter of about $65-125 \mathrm{~nm}$. The bioaerosols with a diameter of $1-5 \mu \mathrm{m}$ are the most potent in terms of airborne transmission of diseases (Wang and Du, 2020). In a study by Xu et al. (2020a), aerosols generated from infectious feces are also thought to drive the spreading of the virus. Altogether, the load pathogenic bioaerosol in the ambient air has been shown to retain its viability for up to 3 hours. This is suspected to play a major role in the transmission of this deadly virus.

Available knowledge and epidemiological studies indicate that the recommended distance of $2 \mathrm{~m}$ to prevent the spread of COVID-19 might be inadequate or effective only if everyone wears a facemask (Setti et al., 2020). In the studies carried out in Wuhan and Nebraska university hospital, SARS-CoV-2 RNA was found in ambient air samples, proving that the virus stayed viable inside aerosol droplets. In a study by van Doremalen et al. (2020), the half-life of SARS-CoV-2 RNA suspended in the ambient air was found to be 1 hour. According to literature, the aerosol size distribution and prevailing wind conditions can support the transportation of contaminated aerosols for up to $10 \mathrm{~m}$. Contaminated aerosols merge with $\mathrm{PM}_{2.5}$ at high concentrations and stable atmospheric conditions further aiding in the transportation and deposition of the viruses in the deeper regions of the human airways (Chen et al., 2017). Indoor environments with low temperature and low relative humidity can lead to rapid evaporation rates at the surface of aerosol droplets forming smaller droplets that can stay airborne for longer. Bioaerosol motion in the transmission of the disease has been an important object in recent investigations. Therefore, future studies might apply 3D human airways models from COVID-19 survivors to determine the motion and DEs of aerosols such as suspended toxic particulates $\left(\mathrm{PM}_{10}\right.$ and $\left.\mathrm{PM}_{2.5}\right)$ and pharmaceutical aerosols in the deformed airways.

In the study of disease exposure through inhalation of bioaerosols, it is important to establish the relationship between viability if the virus, diameter of the bioaerosols, and distance travelled by the bioaerosol in the ambient air. For COVID-19, that is still in debate. But earlier studies have shown that it may vary depending on prevailing wind speed and presence of obstructions.

Even though the novel SARS-CoV-2 virus has affected the world for more than 5 months now, several unknowns have inhibited the full assessment of the situation in the world with regards to the spread of the virus. Amongst them is the minimum viral load required to cause an infection. There is also a need to carry out investigations on the transport analysis to verify if the spread of the virus is airborne. Demystifying the unknowns is vital for proper epidemic control strategies.

\section{OUTLOOK}

\section{Recent Advancements in the Field}

Although many numerical modeling methods have been developed in the past, CFD has now become a categorically 
influential and universal tool for many applications in the $21^{\text {st }}$ century. This is mostly due to its ability to provide solutions representing a rich blend of numerical methods, user interfaces, mathematical physics, and state-of-the-art visualization systems (Xia and Sun, 2002). The recent adoption of CFD for applications in particulate matter and airflow in airways has been driven by the high costs associated with experimentation and analytical modeling methods for solving fluid flow and two-phase flow problems. The trend has been fueled further by the recent development of numerical solutions for Navier-stokes equations and advancement in computing technology, making it a viable option for application in industry and science (Norton and Sun, 2006).

Understanding airflow and particle deposition in obstructed and healthy airways are complex processes. Developing relatively simple equations for predicting the two phenomena would help in building up an improved understanding of the correlation between deposition in the respiratory tract and a wide range of health outcomes.

A possible potential application of the findings from CFD simulations could be in the development of diagnostic techniques based on the images of airflow patterns in the lungs. Breakthroughs in the field of CFD involving human airway geometries could be applied to design more efficient delivery methods for inhaled pharmaceuticals and to also understand the adverse health effects induced by toxic air pollutants for instance use of enhanced condensational growth and eventual deposition.

\section{Challenges}

Although histological measurements are usually included in the generation of geometries to represent obstructed airways, accurate representations of the exact architectures associated with such obstructions are not easily achievable. This is because smooth surfaces are usually applied to connect healthy portions of the airway to the ones affected by obstructions and hence affecting the validity of the results. During the simulations, a $100 \%$ trapping efficiency is assumed, but this might not be the case in real life. The real value would be established best using empirical approaches. CT scanned images of the human lung are clear enough for application in 3D modeling only up to G7, this leaves the rest of the generation depending on idealized human geometries for studies. Despite some previous attempts towards studying the entire human lung, so far, none of the studies has been successful. The complexity of human airways and breathing processes limit the application of in vitro measurements to only two consecutive branches of the human airway. In most numerical simulations, the walls of the human airway are assumed to be stationary. However, this is not the case in reality as the airway walls move in and out during inhalation and exhalation. So far, numerical analysis of two-phase flow inside the human airways uses one-way coupling whereby the gas phase affects the solid or liquid phase but there is no feedback. However, in reality, there should be a reaction force for every action force and this would impact the aerosols' trajectories and eventually change the deposition fractions of particles under investigation.

\section{CONCLUSIONS}

In vitro experiments for estimating deposition of particles in the human airway geometries uses constant velocity at the inlet of the geometry. Even though experiments have helped scientists develop empirical methods for evaluations of the respiratory system, it is the subsequent development of CFD that has proved to be an important tool for the evaluation of airflow and particulate matter deposition in the human airways when applied for localized deposition. Algebraic deposition models came before CFD methods, but their tendency to overestimate the effects of impaction on particle deposition led to the development and more extensive adoption of the CFD method which has higher accuracies. Complex physical phenomena can be broken down in CFD and derived from otherwise inaccessible regions for one applying experiments. The two most popular human airway models are Weibel and Horsfield. The former finds more applications due to its simplicity, accuracy as well as saving on computational costs. For diseased human airway geometries, asthmatic human airways are usually represented by uniformly distributed folds along the circumference of the affected generation, while COPD geometries consist of an axisymmetric constriction in one or more of the bifurcations affected by the obstruction. In the discretization of the human airway geometry for numerical investigations, the following mesh types can apply, unstructured, hexahedral, tetrahedral, non-orthogonal blocks, and triangular prism. The tremendous improvements in CFD methods have placed them on the verge of fully replacing experimental studies. Important factors in carrying out a numerical analysis for instance; computational cost and time are mentioned as some of the most important factors to consider in a numerical simulation. Unlike the central and lower sections of the human airways where the flow is usually laminar, the upper section of the lungs is associated with turbulent airflow. Density-based coupled solvers (DBCS) have high computational costs. Consequently, pressure-based coupled solvers (PBCS) are more popular for investigations of fluid flow inside the human airways. Due to the similarity between real inhalation curves and sinewave curves, some studies have used velocity distribution at the inlet in the form of a sinewave. A uniform velocity distribution is usually imposed at the inlet for simulations in the upper section of the human airways. However, for the central and lower branches, a parabolic velocity distribution is more suitable. The dominance of the 5 main deposition mechanisms, including turbulent mixing, inertial impaction, gravitational sedimentation, Brownian motion, and electrostatic precipitation, vary as the particles advance from the oral cavity, through the upper, central, and lower sections of the human lungs, and later into the alveolar region. Due to the bifurcating nature of human airways, the inhalation segment of the breathing cycle provides a larger surface area for particle deposition through impaction as compared to the exhalation phase. the diameter of inhaled aerosols is directly linked to the Stokes number of the particles for a constant density. The recent development of pneumonia caused by SARS-CoV-2 virus affects patients whereby, they suffer from a serious inflammation of the 
lungs after which the alveoli are filled with water, pus, and debris from epithelial cells destroyed by the immune system in the process of fighting the infection. Therefore, future studies might apply 3D human airways models from COVID-19 survivors to determine the motion and DEs of aerosols such as suspended toxic particulates $\left(\mathrm{PM}_{10}\right.$ and $\left.\mathrm{PM}_{2.5}\right)$ and pharmaceutical aerosols in the deformed airways.

\section{ACKNOWLEDGMENTS}

The authors acknowledge financial support from the Ministry of Science and Technology Taiwan, ROC, under the grant numbers MOST 108-2221-E-006-127-MY3, 1082622-E-006-017-CC1 and 109-3116-F-006-016-CC1 for this research.

\section{REFERENCES}

Adeloye, D., Chua, S., Lee, C., Basquill, C., Papana, A., Theodoratou, E., Nair, H., Gasevic, D., Sridhar, D. and Campbell, H. (2015). Global and regional estimates of COPD prevalence: Systematic review and meta-analysis. J. Glob. Health5: 020415. https://doi.org/10.7189/jogh.0 5.020415

Agostini, A., Floridi, C., Borgheresi, A., Badaloni, M., Pirani, P.E., Terilli, F., Ottaviani, L. and Giovagnoni, A. (2020). Proposal of a low-dose, long-pitch, dual-source chest CT protocol on third-generation dual-source CT using a tin filter for spectral shaping at $100 \mathrm{kVp}$ for CoronaVirus Disease 2019 (COVID-19) patients: A feasibility study. Radiol. Med. 125: 365-373. https://doi.org/10.1007/s11547-020-01179-x

Asadi, S., Bouvier, N., Wexler, A.S. and Ristenpart, W.D. (2020). The coronavirus pandemic and aerosols: Does COVID-19 transmit via expiratory particles? Aerosol Sci. Technol. 54: 635-638. https://doi.org/10.1080/02786826. 2020.1749229

Asgharian, B., Hofmann, W. and Bergmann, R. (2001). Particle deposition in a multiple-path model of the human lung. Aerosol Sci. Technol. 34: 332-339. https://doi.org/ 10.1080/02786820119122

Bilek, A.M., Dee, K.C. and Gaver III, D.P. (2003). Mechanisms of surface-tension-induced epithelial cell damage in a model of pulmonary airway reopening. $J$. Appl. Physiol. 94: 770-783. https://doi.org/10.1152/jappl physiol.00764.2002

Brook, R.D., Rajagopalan, S., Pope, C.A., Brook, J.R., Bhatnagar, A., Diez-Roux, A.V., Holguin, F., Hong, Y., Luepker, R.V. and Mittleman, M.A. (2010). Particulate matter air pollution and cardiovascular disease: An update to the scientific statement from the American Heart Association. Circulation 121: 2331-2378. https://doi.org/ 10.1161/cir.0b013e3181dbece1

Chalupa, D.C., Morrow, P.E., Oberdörster, G., Utell, M.J. and Frampton, M.W. (2004). Ultrafine particle deposition in subjects with asthma. Environ. Health Perspect. 112: 879. https://doi.org/10.1289/ehp.6851

Chang, H. and El Masry, O.A. (1982). A model study of flow dynamics in human central airways. Part I: Axial velocity profiles. Resp. Physiol. 49: 75-95. https://doi.org/ 10.1007/s11547-020-01179-x

Chen, G., Zhang, W., Li, S., Williams, G., Liu, C., Morgan, G.G., Jaakkola, J.J. and Guo, Y. (2017). Is short-term exposure to ambient fine particles associated with measles incidence in China? A multi-city study. Environ. Res. 156: 306-311. https://doi.org/10.1016/j.envres.2017.03.046

Chen, N., Zhou, M., Dong, X., Qu, J., Gong, F., Han, Y., Qiu, Y., Wang, J., Liu, Y. and Wei, Y. (2020). Epidemiological and clinical characteristics of 99 cases of 2019 novel coronavirus pneumonia in Wuhan, China: A descriptive study. Lancet 395: 507-513. https://doi.org/1 0.1016/S0140-6736(20)30211-7

Chen, S., Cui, K., Yu, T.Y., Chao, H.R., Hsu, Y.C., Lu, I.C., Arcega, R.D., Tsai, M.H., Lin, S.L. and Chao, W.C. (2019). A big data analysis of $\mathrm{PM}_{2.5}$ and $\mathrm{PM}_{10}$ from low cost air quality sensors near traffic areas. Aerosol Air Qual. Res. 19: 1721-1733. https://doi.org/10.4209/aaqr.2 019.06.0328

Chen, W.H. (2001a). Dynamics of sulfur dioxide absorption in a raindrop falling at terminal velocity. Atmos. Environ. 35: 4777-4790. https://doi.org/10.1016/S1352-2310(01) 00274-6

Chen, W.H. (2001b). Unsteady absorption of sulfur dioxide by an atmospheric water droplet with internal circulation. Atmos. Environ. 35: 2375-2393. https://doi.org/10.1016/ S1352-2310(00)00536-7

Chen, W.H. (2002). An analysis of gas absorption by a liquid aerosol in a stationary environment. Atmos. Environ. 36: 3671-3683. https://doi.org/10.1016/S13522310(02)00244-3

Chen, W.H., Chen, Y.Y. and Hung, CI. (2011). A Simplified model of predicting $\mathrm{SO}_{2}$ absorption by single atmospheric raindrops with chemical dissociation and internal circulation. Aerosol Air Qual. Res. 11: 860-872. https://doi.org/10.42 09/aaqr.2011.08.0130

Chen, W.H., Lee, K.H., Mutuku, J.K. and Hwang, C.J. (2018a). Flow dynamics and $\mathrm{PM}_{2.5}$ deposition in healthy and asthmatic airways at different inhalation statuses. Aerosol Air Qual. Res. 18: 866-883. https://doi.org/10.4 209/aaqr.2018.02.0058

Chen, X., Zhong, W., Sun, B., Jin, B. and Zhou, X. (2012). Study on gas/solid flow in an obstructed pulmonary airway with transient flow based on CFD-DPM approach. Powder Technol. 217: 252-260. https://doi.org/10.1016/ j.powtec.2011.10.034

Chen, X., Feng, Y., Zhong, W., Sun, B. and Tao, F. (2018b). Numerical investigation of particle deposition in a triple bifurcation airway due to gravitational sedimentation and inertial impaction. Powder Technol. 323: 284-293. https://doi.org/10.1016/j.powtec.2017.09.050

Chen, Z., Jena, S.K., Giridharan, G.A., Koenig, S.C., Slaughter, M.S., Griffith, B.P. and Wu, Z.J. (2018c). Flow features and device-induced blood trauma in CF-VADs under a pulsatile blood flow condition: A CFD comparative study. Int. J. Numer. Methods Biomed. Eng. 34: e2924. https://dx.doi.org/10.1002\%2Fcnm.2924

Cheng, Y.S., Zhou, Y. and Chen, B.T. (1999). Particle deposition in a cast of human oral airways. Aerosol Sci. 
Technol. 31: 286-300. https://doi.org/10.1080/02786829 9304165

Chowdhury, P.H., Honda, A., Ito, S., Okano, H., Onishi, T., Higashihara, M., Okuda, T., Tanaka, T., Hirai, S. and Takano, H. (2019). Effects of ambient $\mathrm{PM}_{2.5}$ collected using cyclonic separator from Asian cities on human airway epithelial cells. Aerosol Air Qual. Res. 19: 18081819. https://doi.org/10.4209/aaqr.2019.01.0016

Çinkooğlu, A., Bayraktaroğlu, S. and Savaş, R. (2020). Lung changes on chest CT during 2019 novel coronavirus (COVID-19) Pneumonia. Eur. J. Breast Health 16: 89. https://dx.doi.org/10.5152\%2Fejbh.2020.010420

Cohen, A.J., Ross Anderson, H., Ostro, B., Pandey, K.D., Krzyzanowski, M., Künzli, N., Gutschmidt, K., Pope, A., Romieu, I. and Samet, J.M. (2005). The global burden of disease due to outdoor air pollution. J. Toxicol. Environ. Health Part A 68: 1301-1307. https://doi.org/10.1080/15 287390590936166

Comer, J., Kleinstreuer, C., Hyun, S. and Kim, C. (2000). Aerosol transport and deposition in sequentially bifurcating airways. J. Biomech. Eng. 122: 152-158. https://doi.org/ $10.1115 / 1.429636$

Darquenne, C. (2012). Aerosol deposition in health and disease. J. Aerosol Med. Pulm. Drug Del. 25: 140-147. https://dx.doi.org/10.1089\%2Fjamp.2011.0916

Delvadia, R.R., Longest, P.W. and Byron, P.R. (2012). In vitro tests for aerosol deposition. I: Scaling a physical model of the upper airways to predict drug deposition variation in normal humans. J. Aerosol Med. Pulm. Drug Del. 25: 32-40. https://doi.org/10.1089/jamp.2011.0905

Deng, Q., Ou, C., Chen, J. and Xiang, Y. (2018). Particle deposition in tracheobronchial airways of an infant, child and adult. Sci. Total Environ. 612: 339-346. https://doi.org/10.1016/j.scitotenv.2017.08.240

Ferron, G., Oberdörster, G. and Henneberg, R. (1989). Estimation of the deposition of aerosolized drugs in the human respiratory tract due to hygroscopic growth. $J$. Aerosol Med. 2: 271-284. https://doi.org/10.1089/jam.19 89.2.271

Finlay, W.H. and Martin, A.R. (2008). Recent advances in predictive understanding of respiratory tract deposition. $J$. Aerosol Med. Pulm. Drug Del. 21: 189-206. https://doi.org/10.1089/jamp.2007.0645

Fisher, A.B., Chien, S., Barakat, A.I. and Nerem, R.M. (2001). Endothelial cellular response to altered shear stress. Am. J. Physiol. Lung Cell. Mol. Physiol. 281: L529L533. https://doi.org/10.1152/ajplung.2001.281.3.1529

Garcia, C., Prota, L., Morales, M., Romero, P., Zin, W. and Rocco, P. (2006). Understanding the mechanisms of lung mechanical stress. Braz. J. Med. Biol. Res. 39: 697-706. https://doi.org/10.1590/S0100-879X2006000600001

Gemci, T., Ponyavin, V., Chen, Y., Chen, H. and Collins, R. (2008). Computational model of airflow in upper 17 generations of human respiratory tract. J. Biomech. 41: 2047-2054. https://doi.org/10.1016/j.jbiomech.2007.12. 019

Guha, A., Pradhan, K. and Halder, P.K. (2016). Finding order in complexity: A study of the fluid dynamics in a three-dimensional branching network. Phys. Fluids 28:
123602. https://doi.org/10.1063/1.4971315

Guha, A. and Pradhan, K. (2017). Secondary motion in three-dimensional branching networks. Phys. Fluids 29: 063602. https://doi.org/10.1063/1.4984919

Guzman, M. (2020). Bioaerosol size effect in COVID-19 transmission. Preprints 2020: 2020040093. https://doi.org/ 10.20944/preprints202004.0093.v1

Hammersley, J.R. and Olson, D. (1992). Physical models of the smaller pulmonary airways. J. App. Physiol. 72: 2402-2414. https://doi.org/10.1152/jappl.1992.72.6.2402

Han, Z., Weng, W. and Huang, Q. (2013). Characterizations of particle size distribution of the droplets exhaled by sneeze. J. R. Soc. Interface 10: 20130560. https://doi.org/ 10.1098/rsif.2013.0560

Häußermann, S., Bailey, A., Bailey, M., Etherington, G. and Youngman, M. (2002). The influence of breathing patterns on particle deposition in a nasal replicate cast. $J$. Aerosol Sci. 33: 923-933. https://doi.org/10.1016/S00218502(02)00044-7

Hofmann, W., Balásházy, I. and Koblinger, L. (1995). The effect of gravity on particle deposition patterns in bronchial airway bifurcations. J. Aerosol Sci. 26: 11611168. https://doi.org/10.1016/0021-8502(95)00044-D

Horsfield, K. and Cumming, G. (1967). Angles of branching and diameters of branches in the human bronchial tree. Bull. Math. Biol. 29: 245-259. https://doi.org/10.1007/BF 02476898

Horsfield, K. and Cumming, G. (1968). Morphology of the bronchial tree in Man. J. Appl. Physiol. 24: 373-383. https://doi.org/10.1152/jappl.1968.24.3.373

Horsfield, K., Dart, G., Olson, D.E., Filley, G.F. and Cumming, G. (1971). Models of the human bronchial tree. J. Appl. Physiol. 31: 207-217. https://doi.org/10.115 2/jappl.1971.31.2.207

Hosseiny, M., Kooraki, S., Gholamrezanezhad, A., Reddy, S. and Myers, L. (2020). Radiology perspective of coronavirus disease 2019 (COVID-19): Lessons from severe acute respiratory syndrome and Middle East respiratory syndrome. Am. J. Roentgenol. 214: 10781082. https://doi.org/10.2214/AJR.20.22969

Huang, J. and Zhang, L. (2011). Numerical simulation of micro-particle deposition in a realistic human upper respiratory tract model during transient breathing cycle. Particuology 9: 424-431. https://doi.org/10.1016/j.partic. 2011.02.004

Hughes, J., Hoppin Jr, F. and Mead, J. (1972). Effect of lung inflation on bronchial length and diameter in excised lungs. J. Appl. Physiol. 32: 25-35. https://doi.org/10.1152 /jappl.1972.32.1.25

Hussain, M., Madl, P. and Khan, A. (2011). Lung deposition predictions of airborne particles and the emergence of contemporary diseases. Part-I. theHealth 2: 51-59.

Hwang, S.H. and Park, D.U. (2019). Ambient endotoxin and chemical pollutant $\left(\mathrm{PM}_{10}, \mathrm{PM}_{2.5}\right.$, and $\left.\mathrm{O}_{3}\right)$ levels in south Korea. Aerosol Air Qual. Res. 19: 786-793. https://doi.org/10.4209/aaqr.2018.06.0235

Hyatt, R.E. and Wilcon, R.E. (1963). The pressure-flow relationships of the intrathoracic airway in man. J. Clin. Invest. 42: 29-39. https://doi.org/10.1172/jci104693 
Inthavong, K., Choi, L.T., Tu, J., Ding, S. and Thien, F. (2010). Micron particle deposition in a tracheobronchial airway model under different breathing conditions. Med. Eng. Phys. 32: 1198-1212. https://doi.org/10.1016/j.med engphy.2010.08.012

Isabey, D. and Chang, H. (1982). A model study of flow dynamics in human central airways. Part II: Secondary flow velocities. Resp. Physiol. 49: 97-113. https://doi.org/ 10.1016/0034-5687(82)90105-0

Islam, M.S., Paul, G., Ong, H.X., Young, P.M., Gu, Y. and Saha, S.C. (2020). A review of respiratory anatomical development, air flow characterization and particle deposition. Int Environ Res. Public Health 17: 380. https://doi.org/10.3390/ijerph17020380

Kang, M.Y., Hwang, J. and Lee, J.W. (2011). Effect of geometric variations on pressure loss for a model bifurcation of the human lung airway. J. Biomech. 44: 1196-1199. https://doi.org/10.1016/j.jbiomech.2011.02.011

Kelecy, F.J. (2008). Coupling momentum and continuity increases CFD robustness. Ansys Advantage 2: 49-51.

Kleinstreuer, C. and Zhang, Z. (2010). Airflow and particle transport in the human respiratory system. Annu. Rev. Fluid Mech. 42: 301-334. https://doi.org/10.1146/annurevfluid-121108-145453

Kolanjiyil, A.V. and Kleinstreuer, C. (2017). Computational analysis of aerosol-dynamics in a human whole-lung airway model. J. Aerosol Sci. 114: 301-316. https://doi.org/ 10.1016/j.jaerosci.2017.10.001

Kulmala, M., Laakso, L., Lehtinen, K.E.J., Riipinen, I., Dal Maso, M., Anttila, T., Kerminen, V.M., Hõrrak, U., Vana, M. and Tammet, H. (2004). Initial steps of aerosol growth. Atmos. Chem. Phys. 4: 2553-2560. https://doi.org/10.519 4/acp-4-2553-2004

Lambert, A.R., O'shaughnessy, P.T., Tawhai, M.H., Hoffman, E.A. and Lin, C.L. (2011). Regional deposition of particles in an image-based airway model: large-eddy simulation and left-right lung ventilation asymmetry. Aerosol Sci. Technol. 45: 11-25. https://doi.org/10.1080/ 02786826.2010 .517578

Lennon, S., Zhang, Z., Lessmann, R. and Webster, S. (1998). Experiments on particle deposition in the human upper respiratory system. Aerosol Sci. Technol. 28: 464474. https://doi.org/10.1080/02786829808965538

Li, L., Huang, Q., Wang, D.C., Ingbar, D.H. and Wang, X. (2020a). Acute lung injury in patients with COVID-19 infection. Clin. Transl. Med. 10: 20-27. https://doi.org/10. $1002 / \mathrm{ctm} 2.16$

Li, Z., Guo, S., Li, Z., Wang, Y., Hu, Y., Xing, Y., Liu, G., Fang, R. and Zhu, H. (2020b). $\mathrm{PM}_{2.5}$ associated phenols, phthalates, and water soluble ions from five stationary combustion sources. Aerosol Air Qual. Res. 20: 61-71. https://doi.org/10.4209/aaqr.2019.11.0602

Lindsley, W.G., Pearce, T.A., Hudnall, J.B., Davis, K.A., Davis, S.M., Fisher, M.A., Khakoo, R., Palmer, J.E., Clark, K.E. and Celik, I. (2012). Quantity and size distribution of cough-generated aerosol particles produced by influenza patients during and after illness. J. Ocсup. Environ. Hyg. 9: 443-449. https://doi.org/10.1080/15459 624.2012 .684582
Longest, P.W., Vinchurkar, S. and Martonen, T. (2006). Transport and deposition of respiratory aerosols in models of childhood asthma. J. Aerosol Sci. 37: 12341257. https://doi.org/10.1016/j.jaerosci.2006.01.011

Longest, P.W. and Vinchurkar, S. (2007). Validating CFD predictions of respiratory aerosol deposition: Effects of upstream transition and turbulence. J. Biomech. 40: 305316. https://doi.org/10.1016/j.jbiomech.2006.01.006

Longest, P.W., Bass, K., Dutta, R., Rani, V., Thomas, M.L., El-Achwah, A. and Hindle, M. (2019). Use of computational fluid dynamics deposition modeling in respiratory drug delivery. Expert Opin. Drug Del. 16: 7-26. https://dx.doi.org/10.1080\%2F17425247.2019.1551875

Luo, H., Liu, Y. and Yang, X. (2007). Particle Deposition in Obstructed Airways. J. Biomech. 40: 3096-3104. https://doi.org/10.1016/j.jbiomech.2007.03.027

Ma, B. and Lutchen, K.R. (2009). CFD simulation of aerosol deposition in an anatomically based human large-medium airway model. Ann. Biomed. Eng. 37: 271. https://doi.org/ 10.1007/s10439-008-9620-y

Mannino, D.M. and Buist, A.S. (2007). Global burden of COPD: Risk factors, prevalence, and future trends. Lancet 370: 765-773. https://doi.org/10.1016/S0140-6736(07)61 380-4

Mathers, C.D. and Loncar, D. (2006). Projections of global mortality and burden of disease from 2002 to 2030. PLoS Med. 3: e442. https://doi.org/10.1371/journal.pmed.0030 442

McCreanor, J., Cullinan, P., Nieuwenhuijsen, M.J., StewartEvans, J., Malliarou, E., Jarup, L., Harrington, R., Svartengren, M., Han, I.K. and Ohman-Strickland, P. (2007). Respiratory Effects of Exposure to Diesel Traffic in Persons with Asthma. N. Engl. J. Med. 357: 23482358. https://doi.org/10.1056/NEJMoa071535

Moskal, A. and Gradoń, L. (2002). Temporary and spatial deposition of aerosol particles in the upper human airways during breathing cycle. J. Aerosol Sci. 33: 1525-1539. https://doi.org/10.1016/S0021-8502(02)00108-8

Mutuku, J.K. and Chen, W.H. (2018). Flow characterization in healthy airways and airways with chronic obstructive pulmonary disease (COPD) during different inhalation conditions. Aerosol Air Qual. Res. 18: 2680-2694. https://doi.org/10.4209/aaqr.2018.06.0232

Mutuku, J.K., Hou, W.C. and Chen, W.H. (2020). Twophase flow dynamics and $\mathrm{PM}_{2.5}$ deposition in healthy and obstructed human airways during inhalation. Aerosol Air Qual. Res. 20: 1091-1110. https://doi.org/10.4209/aaqr.2 020.03.0107

Nazridoust, K. and Asgharian, B. (2008). Unsteady-state airflow and particle deposition in a three-generation human lung geometry. Inhalation Toxicol. 20: 595-610. https://doi.org/10.1080/08958370801939374

Norton, T. and Sun, D.W. (2006). Computational fluid dynamics (CFD) - an effective and efficient design and analysis tool for the food industry: A review. Trends Food Sci. Technol. 17: 600-620. https://doi.org/10.1016/j.tifs.2 006.05 .004

Nowak, N., Kakade, P.P. and Annapragada, A.V. (2003). Computational fluid dynamics simulation of airflow and 
aerosol deposition in human lungs. Ann. Biomed. Eng. 31: 374-390. https://doi.org/10.1114/1.1560632

Olds, J.L. and Kabbani, N. (2020). Is nicotine exposure linked to cardiopulmonary vulnerability to COVID-19 in the general population? FEBS J. https://doi.org/10.1111/ febs. 15303

Park, S. and Wexler, A. (2007). Particle deposition in the pulmonary region of the human lung: A semi-empirical model of single breath transport and deposition. $J$. Aerosol Sci. 38: 228-245. https://doi.org/10.1016/j.jaeros ci.2006.11.009

Pedley, T. (1977). Pulmonary Fluid Dynamics. Annu. Rev. Fluid Mech. 9: 229-274. https://doi.org/10.1063/1.3517737

Phalen, R.F., Mendez, L.B. and Oldham, M.J. (2010). New Developments in Aerosol Dosimetry. Inhalation Toxicol. 22: 6-14. https://doi.org/10.3109/08958378.2010.516031

Piglione, M.C., Fontana, D. and Vanni, M. (2012). Simulation of particle deposition in human central airways. Eur. $J$. Mech. B. Fluids 31: 91-101. https://doi.org/10.1016/j.eur omechflu.2011.08.003

Qi, S., Li, Z., Yue, Y., van Triest, H.J. and Kang, Y. (2014). Computational Fluid Dynamics Simulation of Airflow in the Trachea and Main Bronchi for the Subjects with Left Pulmonary Artery Sling. BioMed Eng. OnLine 13: 85. https://doi.org/10.1186/1475-925X-13-85

Rahimi-Gorji, M., Pourmehran, O., Gorji-Bandpy, M. and Gorji, T. (2015). CFD simulation of airflow behavior and particle transport and deposition in different breathing conditions through the realistic model of human airways. J. Mol. Liq. 209: 121-133. https://doi.org/10.1016/j.moll iq.2015.05.031

Russo, J., Robinson, R. and Oldham, M.J. (2008). Effects of cartilage rings on airflow and particle deposition in the trachea and main bronchi. Med. Eng. Phys. 30: 581-589. https://doi.org/10.1016/j.medengphy.2007.06.010

Sauret, V., Goatman, K., Fleming, J. and Bailey, A. (1999). Semi-automated tabulation of the 3D topology and morphology of branching networks using CT: Application to the airway tree. Phys. Med. Biol. 44: 1625. https://doi.org/10.1088/0031-9155/44/7/304

Schroter, R. and Sudlow, M. (1969). Flow patterns in models of the human bronchial airways. Respiration Physiol. 7: 341-355. https://doi.org/10.1016/0034-5687( 69)90018-8

Schreck, R. and Mockros, L. (1970). Fluid dynamics in the upper pulmonary airways. AIAA $3^{\text {rd }}$ Fluid and Plasma Dynamics Conference, Los Angeles, California.

Setti, L., Passarini, F., Gennaro, G.D., Barbieri, P., Perrone, M.G., Borelli, M., Palmisani, J., Gilio, A.D., Piscitelli, P. and Miani, A. (2020). Airborne transmission route of COVID-19: Why 2 meters/6 feet of inter-personal distance could not be enough. Int. J. Environ. Res. Public Health 17: 2932. https://doi.org/10.3390/ijerph17082932

Sidhaye, V.K., Schweitzer, K.S., Caterina, M.J., Shimoda, L. and King, L.S. (2008). Shear stress regulates aquaporin-5 and airway epithelial barrier function. PNAS 105: 33453350. https://doi.org/10.1073/pnas.0712287105

Solchenbach, K. and Trottenberg, U. (1988). SUPRENUM: System essentials and grid applications. Parallel Comput. 7:
265-281. https://doi.org/10.1016/0167-8191(88)90047-6

Soni, B. and Aliabadi, S. (2013). Large-scale CFD simulations of airflow and particle deposition in lung airway. Comput. Fluids 88: 804-812. https://doi.org/10.1016/j.compfluid. 2013.06.015

Soriano, J.B., Abajobir, A.A., Abate, K.H., Abera, S.F., Agrawal, A., Ahmed, M.B., Aichour, A.N., Aichour, I., Aichour, M.T.E., Alam, K., Alam, N., Alkaabi, J.M., AlMaskari, F., Alvis-Guzman, N., Amberbir, A., Amoako, Y.A., Ansha, M.G., Antó, J.M., Asayesh, H., ... Vos, T. (2017). Global, regional, and national deaths, prevalence, disability-adjusted life years, and years lived with disability for chronic obstructive pulmonary disease and asthma, 1990-2015: A systematic analysis for the Global Burden of Disease Study 2015. Lancet Respir. Med. 5: 691-706. https://doi.org/10.1016/S2213-2600(17)30293-X

Stapleton, K.W., Guentsch, E., Hoskinson, M. and Finlay, W. (2000). On the suitability of $\mathrm{k}-\varepsilon$ turbulence modeling for aerosol deposition in the mouth and throat: A comparison with experiment. J. Aerosol Sci. 31: 739-749. https://doi.org/10.1016/S0021-8502(99)00547-9

Suh, Y. and Park, J.Y. (2018). Effect of off-plane bifurcation angles of primary bronchi on expiratory flows in the human trachea. Comput. Biol. Med. 95: 63-74. https://doi.org/10. 1016/j.compbiomed.2018.01.014

Sul, B., Wallqvist, A., Morris, M.J., Reifman, J. and Rakesh, V. (2014). A computational study of the respiratory airflow Characteristics in normal and obstructed Human airways. Comput. Biol. Med. 52: 130-143. https://doi.org/ 10.1016/j.compbiomed.2014.06.008

Tena, A., Francos, J., Alvarez, E. and Casan, P. (2015). A three dimensional in silico model for the simulation of inspiratory and expiratory airflow in humans. Eng. Appl. Comput. Fluid Mech. 9: 187-198. https://doi.org/10.1080 /19942060.2015.1004819

Tgavalekos, N.T., Musch, G., Harris, R., Melo, M.V., Winkler, T., Schroeder, T., Callahan, R., Lutchen, K. and Venegas, J. (2007). Relationship between airway narrowing, patchy ventilation and lung mechanics in asthmatics. Eur. Respir. J. 29: 1174-1181. https://doi.org/10.1183/09031 936.00113606

Tian, G., Longest, P.W., Su, G. and Hindle, M. (2011). Characterization of respiratory drug delivery with enhanced condensational growth using an individual path model of the entire tracheobronchial airways. Ann. Biomed. Eng. 39: 1136-1153. https://doi.org/10.1007/s10439-010-0223-Z

Tian, L., Shang, Y., Chen, R., Bai, R., Chen, C., Inthavong, K. and Tu, J. (2017). A combined experimental and numerical study on upper airway dosimetry of inhaled nanoparticles from an electrical discharge machine shop. Part. Fibre Toxicol. 14: 24. https://doi.org/10.1186/s12989017-0203-7

Tsuda, A., Henry, F.S. and Butler, J.P. (2008). Gas and aerosol mixing in the acinus. Respir. Physiol. Neurobiol. 163: 139-149. https://doi.org/10.1016/j.resp.2008.02.010

Valavanidis, A., Fiotakis, K. and Vlachogianni, T. (2008). Airborne particulate matter and human health: Toxicological assessment and importance of size and composition of particles for oxidative damage and carcinogenic 
mechanisms. J. Environ. Sci. Health., Part C 26: 339-362. https://doi.org/10.1080/10590500802494538

van Doremalen, N., Bushmaker, T., Morris, D.H., Holbrook, M.G., Gamble, A., Williamson, B.N., Tamin, A., Harcourt, J.L., Thornburg, N.J. and Gerber, S.I. (2020). Aerosol and surface stability of SARS-CoV-2 as compared with SARS-CoV-1. N. Engl. J. Med. 382: 1564-1567. https://doi.org/10.1056/NEJMc2004973

Van Ertbruggen, C., Hirsch, C. and Paiva, M. (2005). Anatomically based three-dimensional model of airways to simulate flow and particle transport using computational fluid dynamics. J. Appl. Physiol. 98: 970-980. https://doi.org/10.1152/japplphysiol.00795.2004

Velavan, T.P. and Meyer, C.G. (2020). The COVID-19 Epidemic. Trop. Med. Int. Health 25: 278-280. https://doi.org/10.1111/tmi.13383

Viegas, C.A., Ferrer, A., Montserrat, J.M., Barbera, J.A., Roca, J. and Rodriguez-Roisin, R. (1996). Ventilationperfusion response after fenoterol in hypoxemic patients with stable COPD. Chest 110: 71-77. https://doi.org/10.1 378/chest.110.1.71

Walters, D.K. and Luke, W.H. (2010). A method for threedimensional navier-stokes simulations of large-scale regions of the human lung airway. J. Fluids Eng. 132: 051101. https://doi.org/10.1115/1.4001448

Wang, J. and Du, G. (2020). COVID-19 may transmit through aerosol. Ir. J. Med. Sci. https://doi.org/10.1007/s1 1845-020-02218-2

Weibel, E.R. (1963a). Geometric and dimensional airway models of conductive, transitory and respiratory zones of the human lung. In Morphometry of the human lung, Weibel, E.R. (Ed.), Springer, pp. 136-142.

Weibel, E.R. (1963b). Geometry and dimensions of airways of conductive and transitory zones. In Morphometry of the human lung, Weibel, E.R. (Ed.), Springer, pp. 110-135.

Xia, B. and Sun, D.W. (2002). Applications of computational fluid dynamics (CFD) in the food industry: A review. Comput. Electron. Agric. 34: 5-24. https://doi.org/10.1016/S0168-1699(01)00177-6

$\mathrm{Xu}, \mathrm{C}$., Luo, X., Yu, C., and Cao, S.J. (2020). The 2019nCoV epidemic control strategies and future challenges of building healthy smart cities. Indoor Built Environ. 1420326X20910408. https://doi.org/10.1177\%2F142032 6X20910408

Xu, Z., Shi, L., Wang, Y., Zhang, J., Huang, L., Zhang, C., Liu, S., Zhao, P., Liu, H., Zhu, L., Tai, Y., Bai, C., Gao, T., Song, J., Xia, P., Dong, J., Zhao, J., and Wang, F.S. (2020). Pathological findings of COVID-19 associated with acute respiratory distress syndrome. Lancet Respir. Med. 8: 420-422. https://doi.org/10.1016/S2213-2600(20) 30076-X

Yanai, M., Sekizawa, K., Ohrui, T., Sasaki, H. and Takishima, T. (1992). Site of airway obstruction in pulmonary disease: Direct measurement of intrabronchial pressure. J. Appl. Physiol. 72: 1016-1023. https://doi.org/ 10.1152/jappl.1992.72.3.1016

Yang, X., Liu, Y. and Luo, H. (2006). Respiratory flow in obstructed airways. J. Biomech. 39: 2743-2751. https://doi.org/10.1016/j.jbiomech.2005.10.009

Yeates, D.B. and Aspin, N. (1978). A mathematical description of the airways of the human lungs. Respir. Physiol. 32: 91-104. https://doi.org/10.1016/0034-5687(7 8)90102-0

Yeh, H.C. and Schum, G. (1980). Models of human lung airways and their application to inhaled particle deposition. Bull. Math. Biol. 42: 461-480. https://doi.org/10.1016/S0 092-8240(80)80060-7

Yoon, S.H., Lee, K.H., Kim, J.Y., Lee, Y.K., Ko, H., Kim, K.H., Park, C.M. and Kim, Y.H. (2020). Chest radiographic and CT findings of the 2019 novel coronavirus disease (COVID-19): Analysis of nine patients treated in Korea. Korean J. Radiol. 21: 494-500. https://doi.org/10.3348/kjr.2020.0132

Zhang, H. and Papadakis, G. (2010). Computational analysis of flow structure and particle deposition in a single asthmatic human airway bifurcation. J. Biomech. 43: 24532459. https://doi.org/10.1016/j.jbiomech.2010.05.031

Zhang, P., Duan, J., Chen, G. and Wang, W. (2019). Numerical investigation on gas-solid flow in a circumfluent cyclone separator. Aerosol Air Qual. Res. 19: 971-980. https://doi.org/10.4209/aaqr.2018.05.0197

Zhang, X., Kang, J., Chen, H., Yao, M. and Wang, J. (2018). $\mathrm{PM}_{2.5}$ meets blood: In vivo damages and immune defense. Aerosol Air Qual. Res. 18: 456-470. https://doi.org/10.42 09/aaqr.2017.05.0167

Zhang, Z. and Kleinstreuer, C. (2001). Effect of particle inlet distributions on deposition in a triple bifurcation lung airway model. J. Aerosol Med. 14: 13-29. https://doi.org/ 10.1089/08942680152007864

Zhang, Z. and Kleinstreuer, C. (2002). Transient airflow structures and particle transport in a sequentially branching lung airway model. Phys. Fluids 14: 862-880. https://doi.org/10.1063/1.1433495

Zhang, Z., Kleinstreuer, C. and Kim, C. (2002). Gas-solid two-phase flow in a triple bifurcation lung airway model. Int. J. Multiphase Flow 28: 1021-1046. https://doi.org/10. 1016/S0301-9322(02)00011-3

Zhang, Z. and Kleinstreuer, C. (2011). Laminar-to-turbulent fluid-nanoparticle dynamics simulations: Model comparisons and nanoparticle-deposition applications. Int. J. Numer. Methods Biomed. Eng. 27: 1930-1950. https://doi.org/10.1002/cnm.1447

Zhao, W., Zhong, Z., Xie, X., Yu, Q. and Liu, J. (2020). Relation between chest $\mathrm{CT}$ findings and clinical conditions of coronavirus disease (COVID-19) pneumonia: A multicenter study. Am. J. Roentgenol. 214: 1072-1077. https://doi.org/10.2214/AJR.20.22976

Zierenberg, J.R., Halpern, D., Filoche, M., Sapoval, B. and Grotberg, J.B. (2013). An asymptotic model of particle deposition at an airway bifurcation. Math. Med. Biol. 30: 131-156. https://doi.org/10.1093/imammb/dqs002

Received for review, April 30, 2020 Revised, May 22, 2020 Accepted, May 24, 2020 